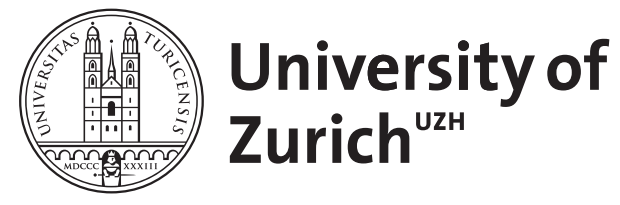

\title{
Spolien in Ravenna - Spolien aus Ravenna: Transformation einer Stadt von der Antike bis in die frühe Neuzeit
}

\author{
Jäggi, Carola
}

Posted at the Zurich Open Repository and Archive, University of Zurich

ZORA URL: https://doi.org/10.5167/uzh-86801

Book Section

Published Version

Originally published at:

Jäggi, Carola (2013). Spolien in Ravenna - Spolien aus Ravenna: Transformation einer Stadt von der Antike bis in die frühe Neuzeit. In: Altekamp, Stefan; Marcks-Jacobs, Carmen; Seiler, Peter. Perspektiven der Spolienforschung 1: Spoliierung und Transposition. Berlin: De Gruyter, 287-330. 


\section{Topoi}

Berlin Studies of the Ancient World

\section{Edited by}

Excellence Cluster Topoi

Volume I5

De Gruyter
Perspektiven der Spolienforschung 1

Spoliierung und Transposition

Herausgegeben von Stefan Altekamp Carmen Marcks-Jacobs

Peter Seiler 


\section{Inhalt}

Einleitung . . . . . . . . . . . . . . . . . . . . . .

\section{Zeithorizont Spätantike}

\section{Karl Leo Noethlichs}

Kaiserzeitliche und spätantike staatliche Regularien zur Spoliierung -

ein Kommentar . . . . . . . . . . . . . . . . . . . .

Troels Myrup Kristensen

The Life Histories of Roman Statuary and Some Aspects of Sculptural

Spoliation in Late Antiquity . . . . . . . . . . . . . . . .

ULRICH GEHN

Phänomene der Spoliierung bei statuarischen Ehrungen in der Spätantike

Maria Fabricius Hansen

The Use of Spolia in Early Christian and Medieval Churches:

Possibilities of Interpretation

ISBN 978-3-II-029090-5

e-ISBN 978-3-1I-029105-6

ISSN 2I9I-5806

Library of Congress Cataloging-in-Publication Data

A CIP catalog record for this book has been applied for at the Library of Congress.

Bibliografische Information der Deutschen Nationalbibliothek

Die Deutsche Nationalbibliothek verzeichnet diese Publikation in der Deutschen Nationalbibliografie; detaillierte bibliografische Daten sind im Internet über http://dnb.dnb.de abrufbar.

(C) 2013 Walter de Gruyter GmbH, Berlin/Boston

Satz: Dörlemann Satz GmbH \& Co. KG, Lemförde

Druck und Bindung: Hubert \& Co. GmbH \& Co. KG, Göttingen

$\infty$ Gedruckt auf säurefreiem Papier

Printed in Germany

\section{Bewegung und Transposition in der Praxis und ihre Bedeutung}

Seth G. Bernard

The Transport of Heavy Loads in Antiquity:

Lifting, Moving and Building in Ancient Rome

VERONICA BIERMANN

Ortswechsel: Überlegungen zur Bedeutung der Bewegung schwerer Lasten für die Wirkung und Rezeption monumentaler Architektur

am Beispiel des Vatikanischen Obelisken . . . . . . . . . . .

\section{Anpassungsleistungen und Umbruchsszenarien}

Stefan Altekamp

Architectural Re-Use Processes in Late Antique North Africa -

Prolegomena . . . . . . . . . . . . . . . . . . . 
Carmen Marciss-Jacobs

Monumente der Vergangenheit im maurischen Spanien -

Überlegungen zu Fragen der Wissenstradition und Funktionskontinuität . 207

Michael Greenhalgh

Cairo: Re-use in Palace, Mausoleum and Mosque:

The Great Diwan "of Saladin" (late I2th century), the Funerary Complex

of Qalawun (1284-5, completed 1304), and the Citadel Mosque of

Al-Nasir Muhammad (I3I8) . . . . . . . . . . . . . . . . . . . . 237

\section{Ortsgebundene Perspektiven}

Dale Kinney

Spoliation in Medieval Rome . . . . . . . . . . . . . . . . 261

CAROLA J̈̈GGI

Spolien in Ravenna - Spolien aus Ravenna:

Transformation einer Stadt von der Antike bis in die frühe Neuzeit . . . . 287

Radikale Rekontextualisierungen

Hans-Rudolf Meine

Rückführungen. Spolien in der zeitgenössischen Architektur . . . . . 333

PAOLO Liverani

Il museo come "Spolienraum" . . . . . . . . . . . . . . . 35 I

Topographisches Register . . . . . . . . . . . . . . . . . 367 


\section{Spolien in Ravenna - Spolien aus Ravenna: Transformation einer Stadt von der Antike bis in die frühe Neuzeit}

Vermutlich ist es die Architektur der Postmoderne, die durch ihren spielerischen Umgang mit älteren Baumotiven und ihre Absage an standardisierte Form-Funktion-Relationen unser Auge für den Spolieneinsatz in historischen Bauten geschärft und in den letzten Jahren zu einer erneuten Intensivierung der Spolienforschung geführt hat. Der Gewinn der jüngeren Spolienforschung liegt dabei nicht so sehr in der Erschließung weiterer Monumente qua Klärung bauarchäologischer Befunde, auch nicht in der Ausdifferenzierung verschiedener Verwendungsmotivationen, sondern in der Erkenntnis, dass Ambiguität in der Spolieninterpretation keinen Malus bedeutet, dem Material vielmehr per definitionem inhärent ist, ja geradezu seine spezifische Qualität darstellt.

Es ist nicht der oft beklagte Mangel an zeitgenössischen Texten, der uns daran hindert, endgültige Antworten auf die Frage nach den „tatsächlichen" Beweggründen für Spolienverwendung zu finden, sondern die spezifische Potenz von Spolien, im Laufe der Zeit verschiedene Bedeutungsschichten anzulagern und dementsprechend unterschiedlich rezipiert zu werden. Zu Recht deklariert Robert Coates-Stephens die während Jahrzehnten die Spolienforschung dominierenden Bemühungen, die Intentionen für Spolienverwendung auf einer imaginären Skala zwischen Ideologie und Pragmatismus zu fixieren, als „largely anachronistic ${ }^{\prime 2}$, denn: „in the ancient world there was just as much ambiguity regarding the question of spolia as there is today amongst art historians and archaeologists. ${ }^{\text {" }}$

Noch nie wurde - genauso wenig wie in der heutigen Forschung - mit einem einheitlichen Blick auf Spolien geschaut, vielmehr kursierten schon immer unterschiedliche Deutungen, bisweilen sogar in derselben Zeit zu demselben Ensemble, verstärkt aber noch in unterschiedlichen Kulturräumen zu unterschiedlichen Zeiten. Selbst im Falle von Spolienbauten, zu denen uns Texte vorliegen, sagen diese nichts Allgemeingültiges aus über Spolienverwendung und -wahrnehmung an sich, sondern nur über die Deutung des betreffenden Befundes zu einer bestimmten Zeit durch eine bestimmte Person. Wie stark diese Deutung über die Jahrhunderte hinweg changieren konnte, zeigen beispielsweise die marmornen Spiralsäulen mit Weinrankendekor in St. Peter in Rom, kostbare Werkstücke des

I Diese Erkenntnis findet sich in den zahlreichen jüngeren Schriften zur Spoliendebatte, v.a. in Kinney r995: Ward-Perkins I999; Meier 2000; Coates-Stephens 2003; Hammer 2005; Kiilerich 2006, I43. Vgl. dagegen Binding 2007, wo die Diskrepanz zwischen (kaum je zu erschließender) Baumotivation und nachträglicher Interpretation exlizit als "Problem" (S. 38) gesehen wird.

2 Coates-Stephens 2003, 342.

3 Coates-Stephens 2003, 352; vgl. auch Coates-Stephens 2002, 279f. 
späten 2. oder frühen 3. Jahrhunderts aus dem kleinasiatischen Raum, die im frühen 4. Jahrhundert von Konstantin für die Ausstattung seiner Memorialkirche über dem Grab des Apostels Petrus geschenkt beziehungsweise im 8. Jahrhundert durch eine Zustiftung seitens des ravennatischen Exarchen Eutychius ergänzt wurden. ${ }^{4}$ Von Konstantin wohl wegen ihrer schieren Schönheit und Kostbarkeit gewählt, wurde ihnen im Laufe des Hochmittelalters eine Herkunft aus dem Apollontempel in Troja angedichtet, was im 14. Jahrhundert von der Legende abgelöst wurde, die Weinrankensäulen stammten aus dem salomonischen Tempel in Jerusalem. ${ }^{5}$

Fälle wie die sog. Pilastri acritani in Venedig - Beutestücke aus Konstantinopel, die im Zuge des vierten Kreuzzugs 1204 in die Lagunenstadt gelangten, in der frühen Neuzeit aber als Trophäen galten, die 1258 den Genuesen in der Schlacht von Akkon abgenommen worden seien - dokumentieren, dass solche Deutungsüberlagerungen keineswegs selten waren. ${ }^{6}$ Als Konsequenz daraus folgt, dass Fragen nach der Bedeutung von Spolien, den Ursachen ihrer Verwendung und ihrer zeitgenössischen Wahrnehmung nie allgemeingültig beantwortet werden können.

If we credit the ancients [...] with the ability to hold a multiplicity of views - the debate over spolia becomes at the same time richer but rather pointless, in that we will never arrive at a conclusive, clear answer to the question, What did the practice actually mean to the ancients?' It did, of course, mean a multitude of things, and must have stretched to meaning, for some people at least, nothing at all.?

Vor diesem Hintergrund kann der Versuch der Berliner Workshop-Organisatoren, „das Phänomen der Spoliierung mit Fragen der Raumforschung zu verbinden", als willkommener Ausweg aus einer Aporie begrüßt werden. Ganz automatisch verlagert sich der Schwerpunkt des Interesses damit auf Transformationsvorgänge, die das Vorher und Nachher genauso mitdenken wie den konkreten Moment der Spolienverwendung. Als "wandernde" Objekte, die sich in Raum und Zeit bewegen, verbinden Spolien Kulturräume, überbrücken Jahrhunderte, kreieren neue Stadträume und implementieren Vergangenheit in die Gegenwart. Sie transportieren Zeit und Raum - eine Qualität, die ihnen kein neues Werkstück abnehmen kann, im Gegensatz zu ideologischen und ästhe-

4 Zur konstantinischen Säulenschenkung s. LP Vita Const. (ed. Duchesne 1886, r76); zu den durch den Exarchen Eutychios an Papst Gregor III. geschenkten Säulen s. LP Vita Gregorii III (ed. Duchesne I886, 4I7); vgl. unten, Anm. 74. Zur Herkunft und Datierung der Säulen s. Ward-Perkins 1952, 24-31; zuletzt Bauer 2009, 6I.

5 Zuletzt: Meier 2000, 90f.; Liverani 2004, 416-418.

6 Meier 2000, 88; zuletzt Tigler 2006. Einen etwas anders gelagerten Parallelfall stellt die Diegesis dar, eine Schriftquelle des 9. Jh., die den justinianischen Säulen in der Hagia Sophia eine Herkunft aus dem römischen Sol-Tempel andichtet, obwohl sie in Tat und Wahrheit Neuanfertigungen aus dem 6. Jh. sind; zuletzt Bauer 2009 $\mathrm{Zu}$ weiteren Fällen s. Esch 2005, 3I

7 Coates-Stephens 2003, 352 . tischen Botschaften, die genauso von ex novo geschaffenen Stücken kommuniziert werden konnten. ${ }^{8}$

Es liegt nahe, in diesem Zusammenhang den Blick auf Gemeinwesen zu werfen, die ihre Wurzeln in der Antike haben und bis heute existieren, die Blütezeiten erlebten und Phasen des Verfalls, die Spolien aktiv verwendeten, aber auch selbst Quelle von Spolienentnahmen wurden. Dass Rom in diesem Zusammenhang stets im Mittelpunkt des In teresses stand, kann angesichts der schieren Menge seiner ererbten Bauten nicht verwundern. Andere spätantike Zentren in Italien haben dagegen nur wenig Aufmerksamkeit bekommen. Nicht, dass der Transformationsprozess, der Städte wie Mailand oder Aquileia in der Spätantike erfasst hat, von der Forschung nicht bemerkt und untersucht worden ist, doch wurde dabei kaum je explizit nach der Rolle von Spolien in diesem Trans formationsprozess gefragt. Dies soll im Folgenden versucht werden, und zwar am Beispiel von Ravenna, der spätantiken Kaiserresidenz, die im 5. und 6. Jahrhundert ihren historischen Höhepunkt erlebte, aber bereits in römischer Zeit bestand und heute eine prosperierende Kleinstadt ist, die wesentliche Anteile ihrer Einkünfte dem Kulturtouris mus - und damit den Monumenten ihrer großen Vergangenheit - verdankt. Während ihrer Hochblüte in der Spätantike spielten Spolien in Ravenna zwar nur eine untergeordnete Rolle, 9 doch bietet das Thema bei genauerer Untersuchung tiefere Einblicke, als bisher aus ihm gewonnen wurden; so wurde z. B. bislang kaum je explizit danach gefragt, wo die Überreste des antiken Ravenna geblieben sind, wohin die Säulen seiner Tempel und die Marmorverkleidung seiner öffentlichen Bauten abgewandert sind. Besser beforsch ist die (Selbst-)Spoliierung Ravennas seit dem Frühmittelalter, vor allem aber der Export ravennatischer Werkstücke durch Karl den Großen und Otto I., doch gibt es auch hierzu Aspekte, die im Kontext der Workshop-Fragestellung eine neue Gewichtung erfahren. ${ }^{10}$

\section{Ravenna als Sitz des weströmischen Kaiserhofes (ca. 402-450):} Spolien, die keine sein wollen

Als der weströmische Hof unter Kaiser Honorius beziehungsweise seinem magister militum Stilicho im Jahre 402 beschloss, die Residenz von Mailand nach Ravenna zu verlegen, fiel die Wahl auf ein römisches Provinzstädtchen, das im Vergleich zu Mailand zwar eine Einbuße an Großstadtflair bedeutete, durch seine Lage in einer Sumpf- und Lagunenland-

8 Vgl. bereits Coates-Stephens 2003, 34I; s. auch Elsner 2000 .

9 Bezeichnend ist etwa die Tatsache, dass Friedrich Wilhelm Deichmann in seinem mehrbändigen Standardwerk zum frühchristlichen und -byzantinischen Ravenna (1958-1989) dem Spolienthema ganze iz Zeilen gewidmet hat; Deichmann I989, 273; vgl, auch Deichmann 1969, I55. In jüngerer Zeit ist es vor allem Rita Zanotto Galli, die sich den Spolien in den spätantiken Bauten Ravennas angenommen hat; Zanotto Galli I995: Zanotto 2007; Zanotto Galli 2009. Vgl. auch Greenhalgh 2009, 79-8r.

Io Ricci rg०9; zuletzt umfassend Ricci r989. 


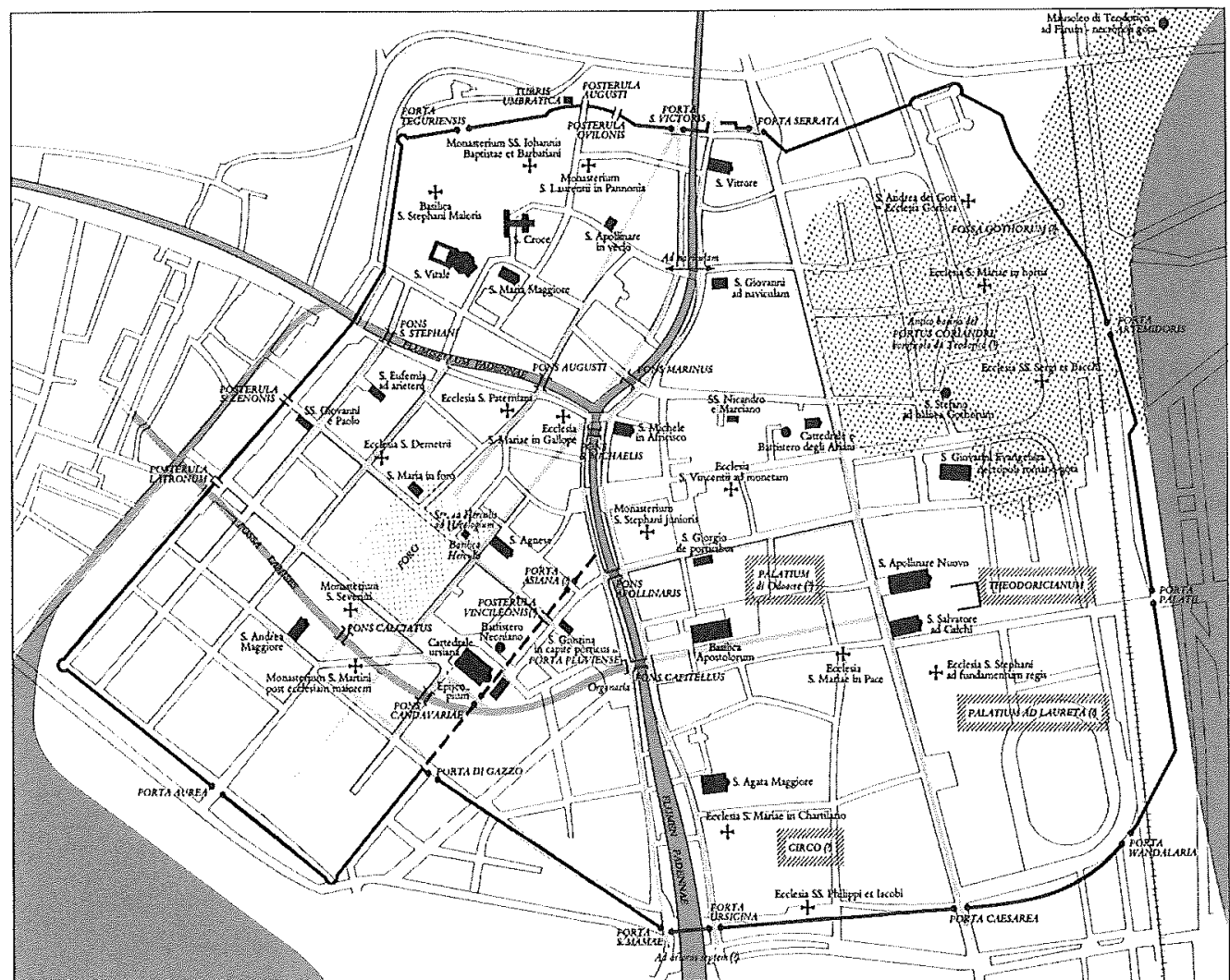

Abb. 1 | Ravenna, Stadtplan mit Eintragung der Bauten und Toponyme aus dem I. Jahrtausend (aus: I Goti, Ausst.-Kat. Mailand I994, S. 237)

schaft aber weitaus besser geschützt war, vor allem aber durch seine enge Anbindung an die Hafenstadt Classe bessere Kommunikationsmöglichkeiten mit dem byzantinischen Kaiserhof sowie im Notfall einen direkten Fluchtweg bereitstellte. ${ }^{\text {II }}$

Ravenna hatte bereits in augusteischer Zeit eine gewisse Bedeutung erlangt, als es zum Stützpunkt jenes Teils der Reichsflotte erkoren wurde, der fortan für die Sicherheit des östlichen Mittelmeerraumes zuständig war. Die Anlage der antiken Kernstadt ist noch heute in Gestalt der sogenannten Ravenna quadrata ablesbar, eines Quartiers im Stadtzentrum, das innerhalb eines südwest-nordost-gerichteten Rechtecks einen auffällig regelmäßigen, orthogonalen Straßenverlauf aufweist (Abb. I).

II Für alle generellen Ausführungen zu Ravenna im 5./6. Jh. verweise ich auf das mehrbändige Monumentalwerk von Deichmann (Deichmann ig 6 , Deichmann I974. Deichmann I976, Deichmann t989). Zuletzt: Jägoi 2010 Deliyannis 20Io. Ich selbst bereite derzeit ein Buch zur Kunst- und Kulturgeschichte Ravennas im 5. und 6. Jh. vor
Reste der Ummauerung dieser Kernstadt konnten archäologisch erfasst werden, ebenso wie Reste von Brücken, die belegen, dass das Stadtgebiet einst maßgeblich von Wasserläufen geprägt war. Von der antiken Innenbebauung haben sich hingegen jegliche Spuren verloren: Die Existenz des Forums, des Kapitols und anderer öffentlicher Bauten aus der frühen und mittleren Kaiserzeit kann heute nur mehr auf der Basis von nachantiken Schriftquellen nachgewiesen werden. So wird etwa das ravennatische Theater erstmals bei Salvian im 5. Jahrhundert erwähnt, der Circus, das Amphitheater und das Forum sogar erst im $7 ., 9$. und Io. Jahrhundert. ${ }^{\mathrm{I2}}$

Auch bei den Tempeln ist die Quellenlage äußerst dünn; ein einziger Tempel - jener des Neptun - wird in einer antiken Inschrift (2. Jahrhundert) genannt, wohingegen das Capitolium und der Apollontempel erstmals im 9. Jahrhundert erwähnt werden. Für den Herkules-, den Drusus- und den Saturntempel wiederum existieren nicht einmal mittelalterliche Überlieferungen - sie begegnen das erste Mal in der antiquarischen Überlieferung des I6.-I9. Jahrhunderts. Ein Caesareum mit einem Altar zu Ehren der julisch-claudischen Herrscherfamilie ist aufgrund von Relieffunden rekonstruierbar, doch bleibt auch für dieses der ehemalige Standort unklar. ${ }^{\mathrm{r}}$ Einzig im Falle des Circus, der jedoch erst im Zuge des spätantiken Stadtausbaus angelegt worden sein dürfte, ist aufgrund des mittelalterlichen Quartiernamens "Circlum" beziehungsweise der heutigen Via del Cerchio eine approximative Lage am Rande des einstigen Palastquartiers zu rekonstruieren.

Es liegt nahe, das fast völlige Verschwinden des römischen Ravenna mit einer großangelegten Selbstspoliierung im Zuge des spätantiken Ausbaues der Stadt zur Kaiserresidenz in Verbindung zu bringen, doch wird diese Vermutung durch die materielle Überlieferung nur partiell bestätigt. Der neue Status Ravennas scheint sich zunächst in einer wesentlichen Vergrößerung der befestigten Siedlungsfläche in nördliche und östliche Richtung niedergeschlagen zu haben, wobei die städtische Bebauung bereits im 2. Jahrhundert die Mauern der alten Ravenna quadrata überschritten hatte.

Unter Honorius ( $\uparrow 423)$, vielleicht aber auch erst unter seinem Nachfolger Valentinian III. (reg. 425-455), erhielt Ravenna einen neuen Befestigungsring, der eine fünf Mal größere Fläche umfasste als die antike Kernstadt; die Ziegel, mit denen die Stadtmauererweiterung realisiert wurde, scheinen zumindest teilweise Spolienziegel gewesen $\mathrm{zu}$ sein. ${ }^{14}$ Ein Großteil der neu befestigten Siedlungsfläche wurde vom Palastbezirk eingenommen, der sich über den ganzen östlichen Teil der Stadt erstreckt haben dürfte. Für den eigentlichen Palast konnte auf ein repräsentatives Gebäude aus der Kaiserzeit zurückgegriffen werden, eine villa suburbana, die bis dahin möglicherweise dem Flottenpräfek-

I2 Quellennachweise bei Deichmann 1989, 27f.; Manzelli 2000, 204-207; Augenti 2008, $97 \mathrm{f}$

13 Lippolis 2000, 264-271

I4 Christie I989, I30 und 136. Zur Stadtmauer Ravennas s. auch Capellini I987; Christie/Gibson I988; Capellini I993: Gelichi 2005. Zum angenommenen Mauerbau unter Honorius s. Deichmann 1989, $36 \mathrm{f}$ 


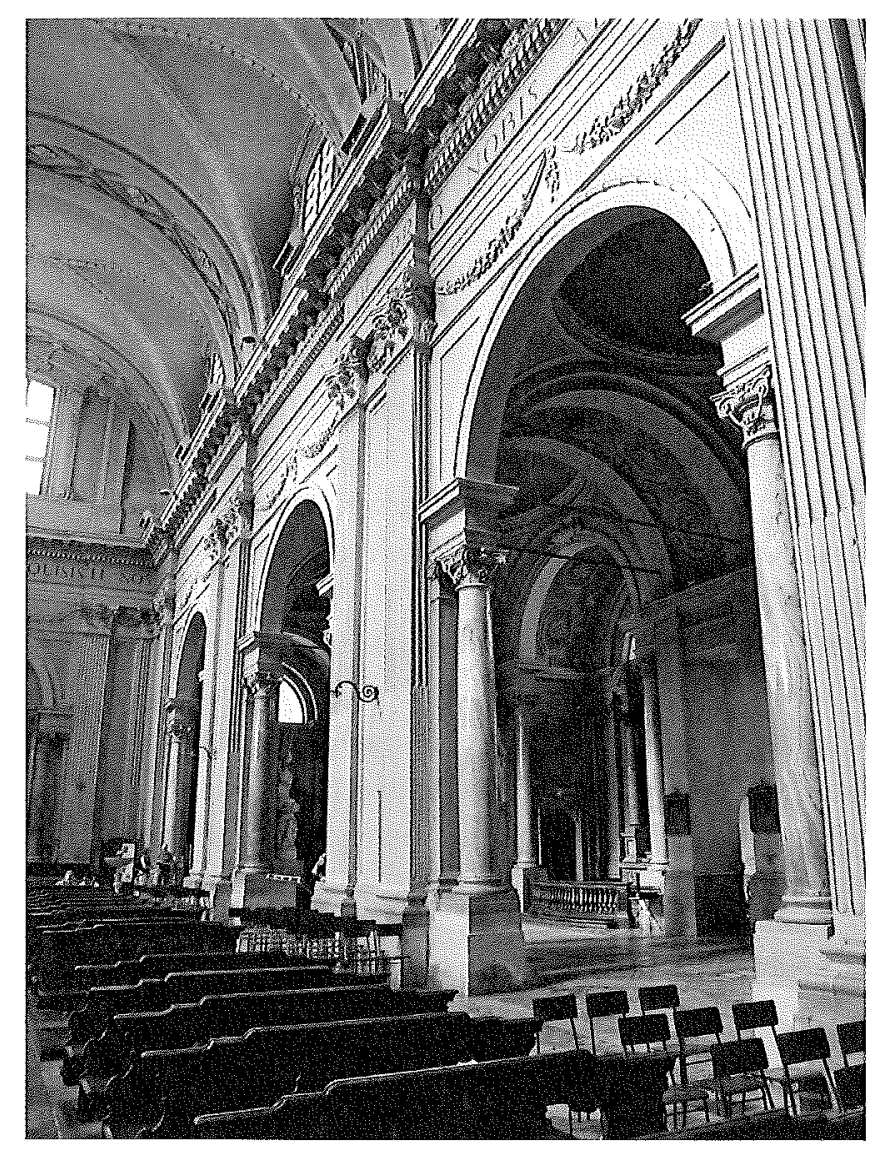

Abb. 2 | Ravenna, Kathedrale, nördliches Seitenschiff, Blick nach Nordwesten (Foto: C. Jäggi)

ten als Amtssitz gedient hatte und nun, nach dessen Verlegung nach Classe um 400, in Hinblick auf ihre neue Aufgabe als palatium für Honorius und seine unmittelbare Entourage um- und ausgebaut wurde. ${ }^{15} \mathrm{Ob}$ dabei auch Spolien aus dem römischen Ravenna zum Einsatz kamen, ist den Unterlagen der Grabungen von I908-I9I4 nicht zu entnehmen; ${ }^{16}$ die Befundinterpretation wird allerdings auch dadurch erschwert, dass der Palastkomplex bis ins mittlere 8. Jahrhundert kontinuierlich weiter genutzt wurde, vermutlich bereits von Odoaker (476-493), dann aber vor allem von Theoderich (493-526) und zwi-

I5 Augenti 2005, 9-23; Zur Vermutung, das Gebäude habe vor der Umnutzung als Kaiserpalast dem Flottenpräfekten als Amtssitz gedient, s. Deichmann Ig89, $32 \mathrm{f}$.

T6 Vgl. Deichmann I989, 58-70. Unter den Funden vom Gelände des ehem. Palastbezirks sind zwar zahlreiche Skulpturen und bauplastische Elemente des I./2. Jhs., doch ist nicht klar, ob diese aus dem kaiserzeitlichen Gebäude am Ort stammen oder in der Spätantike zur Wiederverwendung hierher verbracht wurden; vgl. Berti 1974 und Berti 1975.

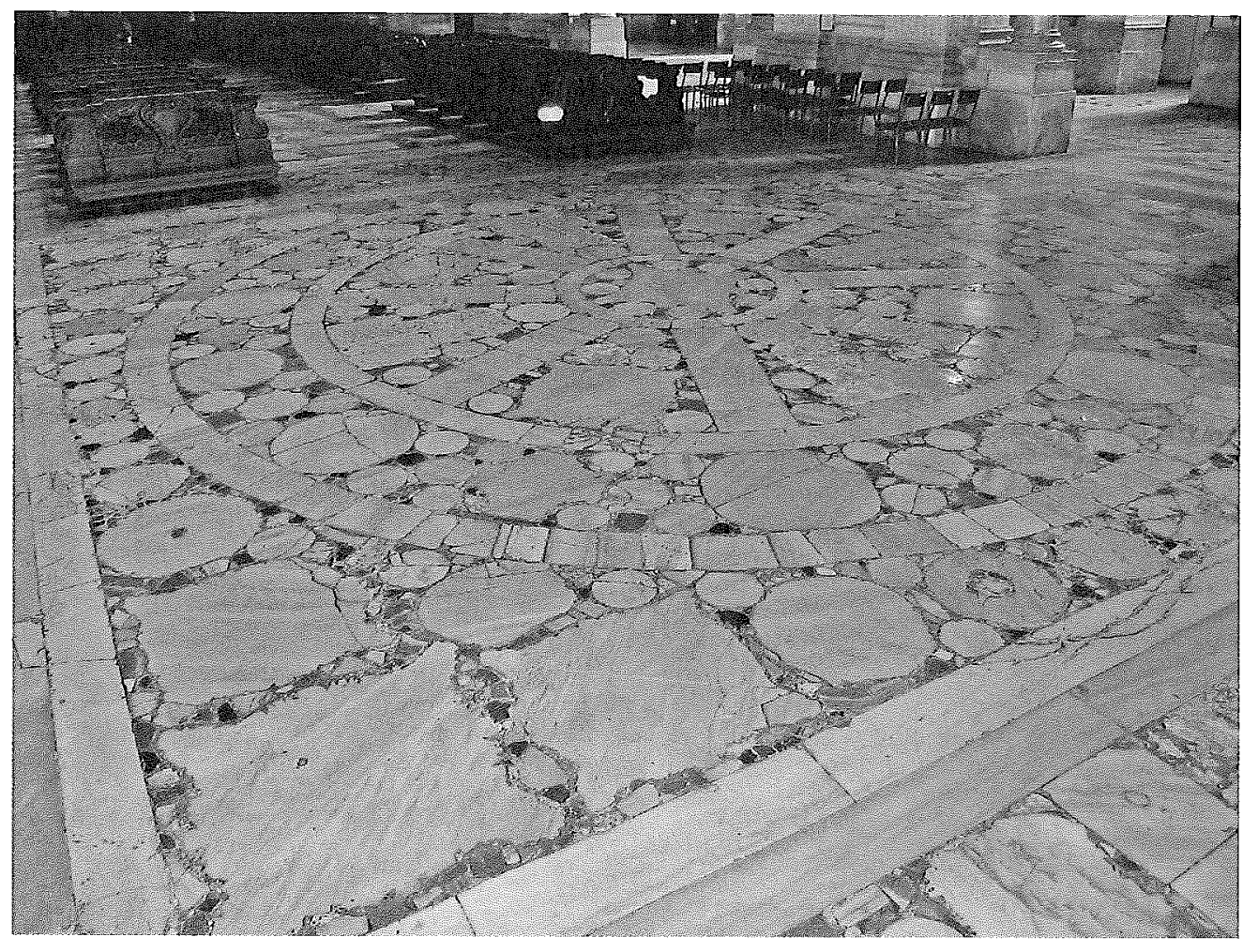

Abb, 3 | Ravenna, Kathedrale: Detail des Fußbodenbelags von 1733-43 (Foto: C. Jäggi)

schen 540 und 75I von den Exarchen, um schließlich durch Karl den Großen spoliiert zu werden. ${ }^{17}$

Unter den Kirchen, die während der I. Hälfte des 5. Jahrhunderts in Ravenna gebaut wurden, sind leider nur die wenigsten in einem Zustand erhalten, der Aussagen über die damalige Verwendung von Spolien zulässt. Die Kathedrale, die vielleicht schon im späten 4. Jahrhundert - und damit noch vor der Aufwertung der Stadt als Kaiserresidenz - am Ostrand der Ravenna quadrata errichtet wurde, musste 1733 einem barocken Neubau weichen, der die Säulenschäfte der frühchristlichen Vorgängerin teilweise tel quel in seine Stützenreihen integrierte (Abb. 2), zum Teil aber auch inklusive der Kapitelle in Scheiben zersägte und diesen im neuen Opus-sectile-Boden ein dekoratives Nachleben bescherte (Abb. 3). ${ }^{18}$

I7 Zur Spoliierung des ravennatischen Palastes durch Karl siehe unten, S. 3I0-312.

I8 Zu den 24 Schäften, die in der barocken Kirche wiederverwendet wurden, s. Deichmann 1974, 6-8; Novara 1997, 78, Zum barocken Fußboden s. Novara 1997, 20-24. Zum vorbarocken Opus-sectile-Boden, in dem viele antike Grabstelen verbaut waren, s. Novara I995a; Romanelli I996, 3If. 


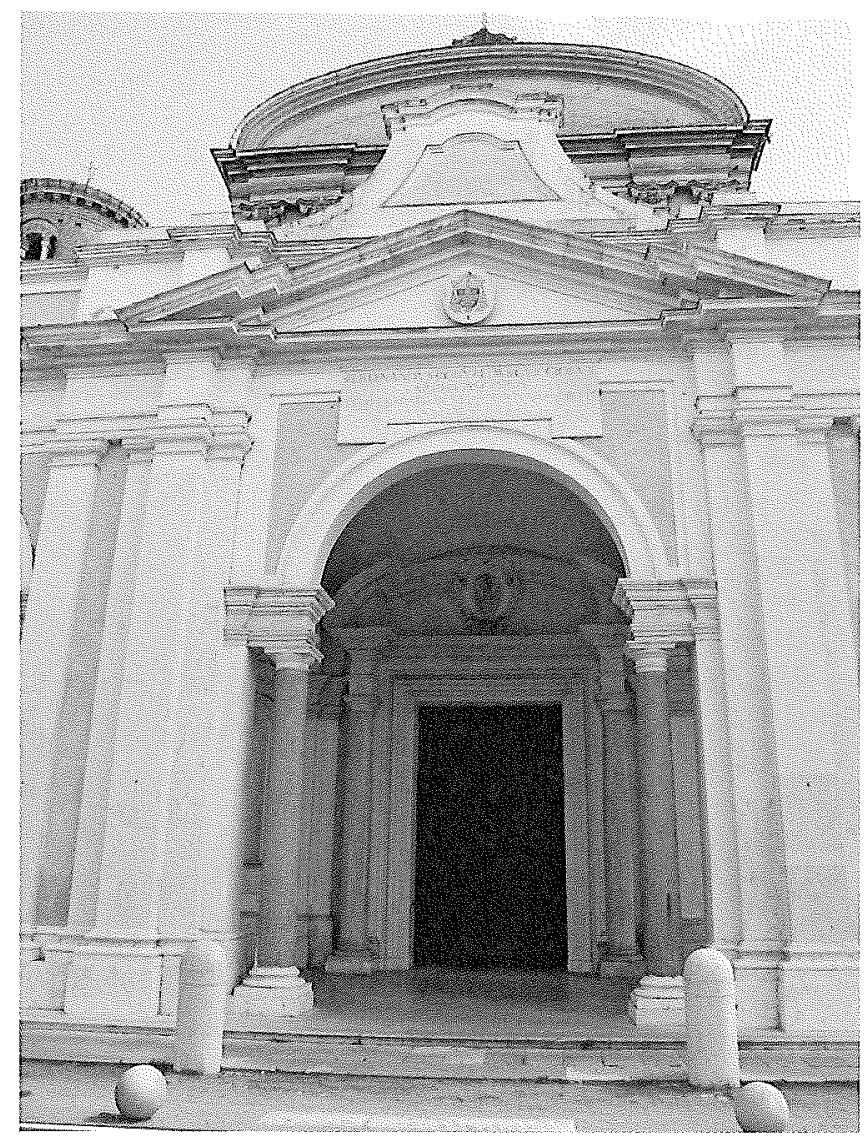

Abb. 4 | Ravenna, Kathedrale, Blick vom Vorplatz auf das mittlere Joch der Vorhalle mit dem Hauptportal (Foto: C. Jäggi)

In Beschreibungen und Skizzen, die vor dem Abbruch der alten Kathedrale aufgenommen wurden, wird diese als fünfschiffige Basilika mit vier Reihen à jeweils I4 Säulen beschrieben; die Schäfte seien alle monolithisch und bestünden aus „marmo greco“, würden aber in Länge und Umfang differieren. ${ }^{19}$ Auch die Kapitelle seien unterschiedlich; unter anderen werden Zweizonenkapitelle mit Adler- und Widderprotomen genannt, die wir in jenen Figuralkapitellen erkennen dürfen, die heute im Museo Arcivescovile aufbewahrt sind. ${ }^{20}$ Zwei von ihnen stammen aus dem späten 5 . Jahrhundert, zwei weitere aus justinianischer Zeit, weshalb sie nicht zur Originalausstattung der frühchristlichen Kathedrale gehören, sondern erst im Zuge einer jüngeren Verschönerungsaktion in die

I9 Quellen zusammengestellt bei Bovini I953; Deichmann I974, 6-8; Novara 1995b, 55I-553; Novara 1997, I45-I70; Zanotto 2007, 7I-75. Von den im heutigen Dom wiederverwendeten Schäften bestehen zwei aus Cipollino, vier aus Bigio antico und i8 aus prokonnesischem Marmor; Novara 1997, 78 .

20 Olivieri Farioli $1969,33-36.50 f$.; Novara $1997,76-78$.
Kirche gelangt sein können. ${ }^{21}$ Dasselbe gilt für die Kapitelle und Kämpfer des 6 . Jahrhunderts, die später in der frühmittelalterlichen Krypta wiederverwendet wurden. ${ }^{22}$ Entsprechende Vorsicht ist auch bei den vier Spoliensäulen in der Vorhalle angebracht (Abb. 4), die heute den Haupteingang des Domes auszeichnen; zwei von ihnen bestehen aus Marmor, die anderen beiden aus rosafarbenem Assuan-Granit. ${ }^{23}$ Es liegt nahe, anzunehmen, dass zwei von ihnen einst den Apsisbogen stützten, doch bleibt ihre Herkunft letztlich im Dunkeln. ${ }^{24}$

Zur Basilica Ursiana gehörte auch ein Baptisterium, das im Unterschied zum Dom bis heute in seiner frühchristlichen Gestalt erhalten ist. ${ }^{25}$ Es handelt sich um einen frei im Norden der Kathedrale stehenden achteckigen Füllnischenzentralbau, der in einer zweiten Phase - unter Bischof Neon in den Jahren nach 450 - anstelle der bis dahin eingezogenen Flachdecke eine Kuppel sowie eine reiche Mosaik- und Stuckausstattung erhielt. Die Blendbogengliederung im Innern scheint hingegen bereits auf die Bauzeit unter Ursus um 400 zurückzugehen, und mit ihr auch die ionischen Kapitelle in der oberen Blendbogenzone; bei den zugehörigen Schäften handelt es sich um Stücke aus unterschiedlichem Material, also wohl Spolienmarmor, wobei nicht klar ist, ob sie einst durch Verstuckung vereinheitlicht waren. ${ }^{26}$ Bei den acht Kapitellen des Erdgeschosses handelt es sich mit Sicherheit um Spolien; sechs von ihnen sind Kompositkapitelle aus severischer Zeit, zwei korinthische Kapitelle des kleinasiatischen Typs aus dem 4. Jahrhundert. ${ }^{27} \mathrm{Da}$ die zugehörigen Basen und Schäfte auf einem Bodenniveau aufliegen, das nicht das ursprüngliche ist, können sie weder dem Ursprungsbau noch der neonianischen Umbauphase angehören, sondern gelangten laut Deichmann erst im Mittelalter an ihren jetzigen Versatzort, ${ }^{28}$ was freilich nicht heißen muss, dass sie erst bei dieser Gelegenheit in den Bau gelangten und nicht schon zuvor dort verbaut waren. Das spolial in der oberen Zone des Tambours verbaute Reiterrelief wiederum, eine Sarkophagwange des 3. Jahrhunderts

2I Deichmann 1974, 5; Novara 1997, 72-76. Eines der Kapitelle stammt evtl. gar nicht aus der Kathedrale, sondern aus S. Apollinare in Classe.

22 Mazzotti 1951; Deichmann I974, 4; Novara 1997, 82

23 Deichmann 1974, 6 beschreibt das Material der beiden Marmorsäulen als „grauen, vielleicht parischen Marmor, mit z.T. ganz weißen Adern" und gibt als Höhe 5,29 bzw. $5,26 \mathrm{~m}$ an; die Schafthöhe der beiden Granitsäulen beträgt lt ihm 479 bzw $4755 \mathrm{~m}$. Laut Novara $1997,78-80$ bestehen die zwei Marmorsäulen aus prokonnesischem Marmor, ihre Höhe gibt sie mit 5,20 m an; die Höhe der 2 Granitsäulen beträgt nach Novara 5,20, doch seien sie beschnitten und dürften ursprünglich 5.80 m hoch gewesen sein.

24 Bovini 1953, 74; Deichmann 1974, 6 und 8; in sich widersprüchlich Novara 1997, 78-80; zuletzt Zanotto

24 Bovini $2007,74 \mathrm{f}$.

$25 \mathrm{Zu}$ den diversen Bodenhöherlegungen und anderen Eingriffen, die auch hier im Laufe der Jahrhunderte erfolgten, s. Deichmann 1974, I9f.

26 Deichmann 1974, 22; Zanotto 2007, 82f.

27 Deichmann 1974, 22; Zanotto 2007, 84. Bei Novara/Sarasini 200I, 93 Untergliederung der sechs Kapitelle in zwei Gruppen; die Stücke der Gruppe I weisen die interessante Anomalität auf, dass sie statt der 4 Eckvoluten 5 aufweisen, also offenbar schon in ihrer Erstverwendung eine Ecksituation betonten.

28 Deichmann I974, 22; vgl. Romanelli 1996, 38-40; Novara/Sarasini 200I, 83; Zanotto 2007, 8I. 

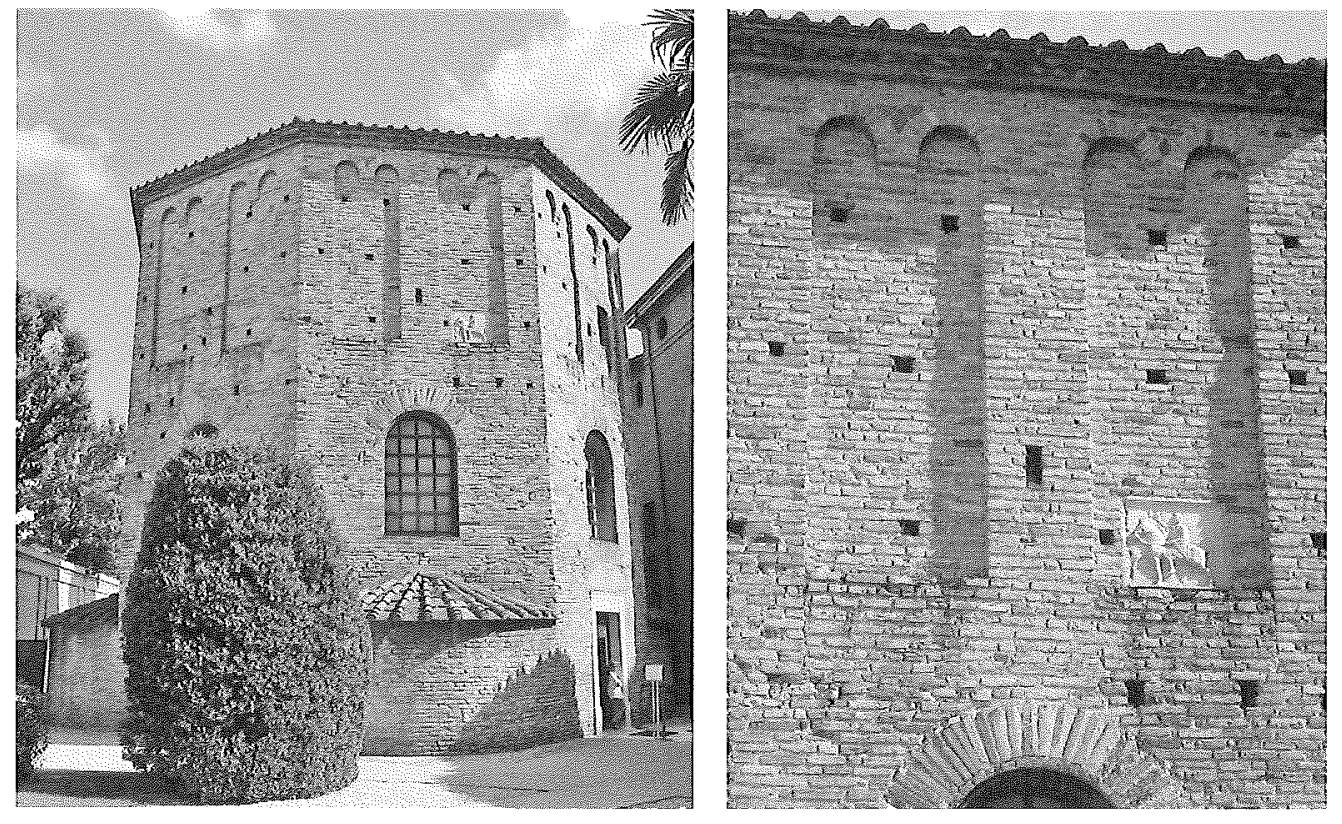

Abb. 5 a.b | Ravenna, Baptisterium der Orthodoxen, Ansicht von Westen: Spolial in der oberen Tambourzone verbautes Relief des 3. Jhs. (Fotos: C. Jäggi)

(Abb. 5 a.b), entzieht sich insofern einer klaren Bewertung, als noch immer umstritten ist, ob diese obere Tambourzone aus dem mittleren 5. Jahrhundert oder aber erst aus dem Hochmittelalter datiert. ${ }^{29}$

Ähnliche Schwierigkeiten in der Überlieferungssituation liegen im Falle von S. Lorenzo und S. Croce vor, beides Stiftungen von Angehörigen des weströmischen Kaiserhauses oder deren engstem Umfeld. S. Lorenzo muss noch vor 425 in Caesarea, dem südlichen Suburbium von Ravenna (Abb. 6), gegründet worden sein, offenbar als Coemeterialkirche mit angebauten Privatmausoleen. ${ }^{\circ}$ Andreas Agnellus, dessen kurz nach 830 kompilierte Bischofschronik die wichtigste Quelle zum frühchristlichen und -mittelalterlichen Ravenna darstellt, beschreibt sie als reich ausgestattet, doch verlieren sich in nachkarolingischer Zeit ihre Spuren, bis sie schließlich kurz nach der Mitte des I6. Jahrhunderts endgültig abgebrochen wurde. ${ }^{3 \mathrm{I}}$ Anlässlich ihres Abbruchs im Jahre $1553 / 4$ ist von 24 beziehungsweise

29 Die Argumente in Bezug auf die Datierung der oberen Tambourzone zusammengestellt bei Zanotto 2007 , 77-79; zuletzt - mit einer Datierung in die Zeit Bischof Neons - Vernia 2009, 53f. Zum Reiterrelief s. Rebecchi 1974, 52 f.; Romanelli 1996, 36-39.

30 Der terminus ante quem ergibt sich aus einer Passage in Sermo 322 von Augustin aus dem Jahr 425; Migne, PL 38, col. I444.

3I LPRav Kap. 35 (Nauerth 1996, I76-179); zum Abbruch im 16. Jh.; siehe unten, S. 318f.

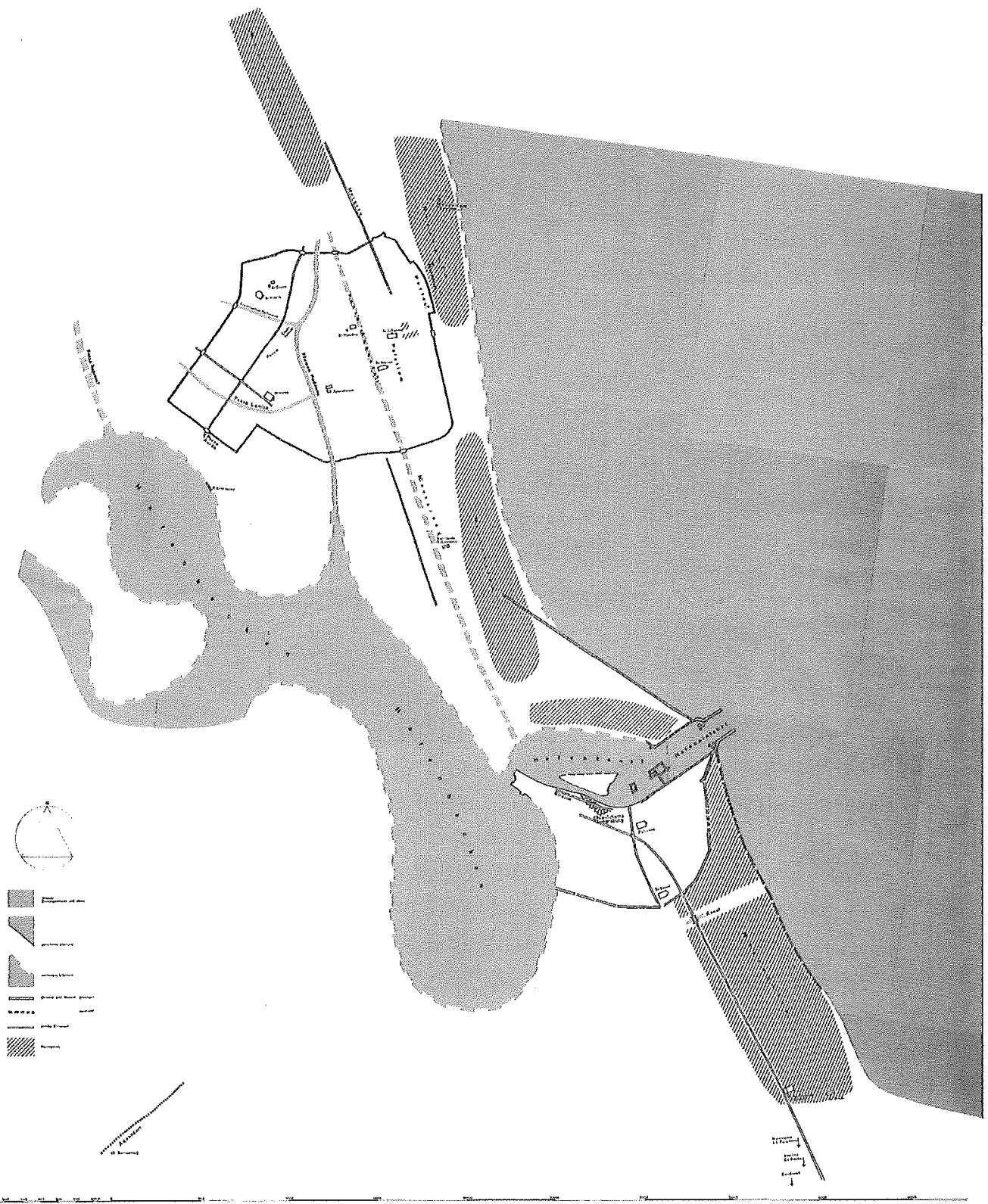

Abb. 6 | Ravenna, Umgebungskarte; Caesarea mit der ehemaligen Laurentiuskirche lag zwischen Ravenna und Classe (aus: Deichmann 1989, P1. I) 
30 Säulen die Rede, die deduzieren lassen, dass es sich bei der Laurentiuskirche um eine dreischiffige Basilika handelte. $3^{22}$ Von den Säulenschäften - aus Cipollino - verblieben zwei in Ravenna, wo sie bis heute das Hauptportal der cinquecentesken Kirche S. Maria in Porto schmücken; die restlichen sollen I553/4 auf Geheiß des Kardinallegaten Girolamo Capodiferro nach Rom geschickt worden sein, wo sich ihre Spur verliert. ${ }^{33}$ Sollte es sich um ein komplettes Set an einheitlichen Cipollinosäulen gehandelt haben, dürfen wir wohl annehmen, dass diese keine Spolien waren, sondern ex novo angefertigte Werkstücke des 5 . Jahr hunderts, die für den Bau der prestigiösen Coemeterialbasilika aus Griechenland importiert wurden.

S. Croce wiederum, vermutlich eine Stiftung von Galla Placidia $(4 \mathrm{I} 6-42 \mathrm{I}$ und 425/6-448/9 in Ravenna residierend), war ursprünglich eine kreuzförmige Kirche mit Außenportiken entlang der Seitenwände. Von der Anlage des 2. Viertels des 5. Jahrhunderts steht heute nur mehr das sogenannte Mausoleum der Galla Placidia aufrecht, ein kleiner kreuzförmiger Bau, der einst am Nordende der Kirchenvorhalle angebaut war. Die heute auf dem Gelände stehende Saalkirche datiert hingegen aus dem II. Jahrhundert und danach.34 Die Gestalt ihrer frühchristlichen Vorgängerin ist durch verschiedene Grabungen bekannt, die nicht nur die Umfassungsmauern und Reste der liturgischen Einbauten sowie des Opus-sectile-Bodens erfasst haben, sondern auch die noch in situ liegenden Basen der südlichen Außenportikus und der Triumphbogensäulen; letztere sind etwas größer dimensioniert und bestehen aus prokonnesischem Marmor, erstere sind etwas kleiner und aus Kalkstein. ${ }^{35}$ Die zugehörigen Schäfte fehlen - ganz offensichtlich wurden sie im Laufe der Jahrhunderte an anderer Stelle wiederverwendet.

$\mathrm{Ob}$ es sich bei den gefundenen Basen um Spolien handelt, ist der Grabungsdokumen tation nicht zu entnehmen; die Tatsache jedoch, dass auch Fragmente von antiken Kalksteinkapitellen auf dem Gelände gefunden wurden, ${ }^{6}$ lässt zumindest die Kalksteinbasen als Spolien ansprechen. Auch im Mauerwerk selbst kamen Spolien zum Einsatz, sei es in Form wiederverwendeter Mauerziegel oder aber einzelner Fragmente von antiken Inschriften, stets jedoch als reines Baumaterial.37 Das einzige ostentativ verbaute antike Werkstück ist der Architravblock aus tiberisch-claudischer Zeit, der mit der Soffitte als Schauseite als Sturzstein über dem heutigen Zugang zum Mausoleum der Galla Placidia liegt (Abb. 7)

32. Deichmann 1976, 340; Novara/Cicognani 1994, 23I.

33 Siehe unten S. 319. In einem Inventar von 1894 werden neben den zwei Cipollino-Säulen noch ein porphyrner Mischkrug (idria), vier Säulen aus griechischem Marmor in der Marienkapelle und vier Säulen aus bigio antico in der Laurentiuskapelle aufgelistet; alle diese Werkstücke sind noch heute in der Kirche, doch ist ihre Herkunft unbekannt; Novara/Cicognani 1994, 239 .

34 Deichmann 1974, 53.

36 Novara 2008, 113-11., 8 , Novara $2008,117-120$

37 Cortesi I978, 54 Anm. 25; Novara 2008, I33f.

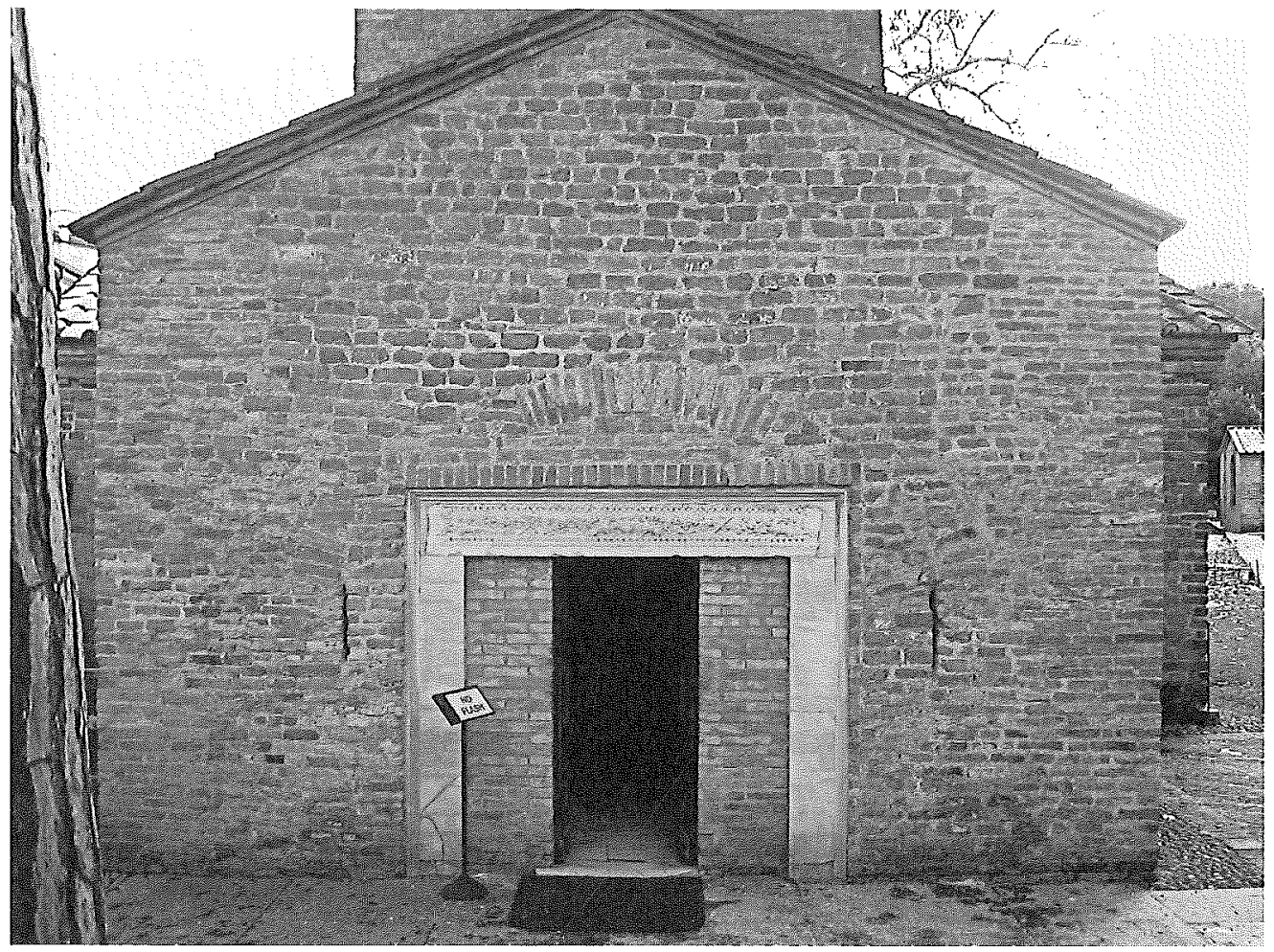

Abb. 7 | Ravenna, sog. Mausoleum der Galla Placidia, Sturz über dem Zugang, Ansicht von Norden (Foto: C. Jäggi)

diese Situation datiert freilich erst aus dem Jahr I899, soll aber eine Situation wiederherstellen, wie sie bis 1754 bestanden hat..$^{38}$

In einer weiteren Kirchengründung Galla Placidias treffen wir dann erstmals auf einen breiteren und planvollen Einsatz von Spolien: in S. Giovanni Evangelista. Die Kaiserin, die ab 425 für und dann mit ihrem Sohn Valentinian III. regierte, ließ diese Kirche in Erfüllung eines Gelübdes errichten, nachdem sie durch den hl. Johannes aus einem Seesturm gerettet worden war, in den sie 425 zusammen mit ihren beiden Kindern bei der Rückkehr aus Konstantinopel nach Ravenna geraten war.

Im Gegensatz zu den vorgenannten Kirchen steht S. Giovanni Evangelista noch heute mehr oder weniger in seiner frühchristlichen Gestalt aufrecht, wenn auch mit massiv erhöhtem Bodenniveau, ein Hinweis, der für alle noch in Funktion stehenden Kirchen Ra-

38 Ricci 1914, 20; Deichmảnn 1974, 66f.; De Maria 2000, 293 (mit Zuweisung ans Theater); Novara/Sarasini 200I, 95; Zanotto 2007, II3-II6 (mit einer vorsichtigen Zuweisung an einen Tempel, außerdem mit dem Hinweis, dass in S. Aquilino in Mailand an vergleichbarer Stelle ein römisches Gesims wiederverwendet ist). 


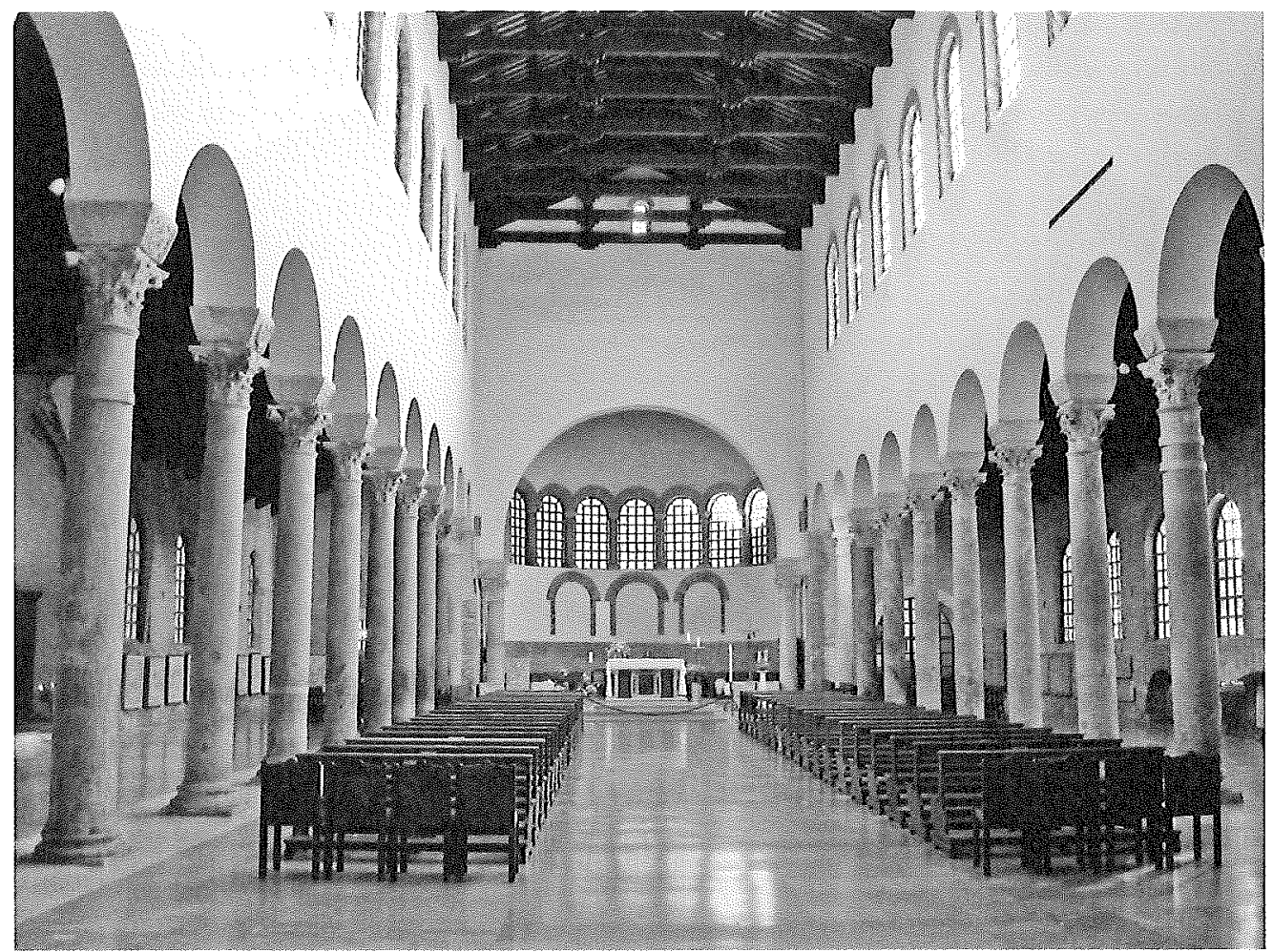

Abb. 8 | Ravenna, S. Giovanni Evangelista, Innenansicht nach Osten (Foto: C. Jäggi)

vennas aus dem I. Jahrtausend gilt. Außerdem besaß sie einst einen Narthex, der eventuell schon im späten 6. Jahrhundert zugunsten einer Verlängerung des Langhauses nach Westen entfernt wurde, sowie eine reiche Mosaikausstattung, die im $\mathrm{I} 6$. Jahrhundert einer Neuausmalung zum Opfer fiel; das heutige, etwas gar „aufgeräumt“ wirkende Gepräge verdankt die Kirche den Purifizierungsmaßnahmen von I9I9-2I und den tiefgreifenden Wiederaufbau- und Restaurierungsarbeiten nach den Bombenschäden von 1944.

Bei S. Giovanni Evangelista handelt es sich um eine dreischiffige Basilika, die in unserem Kontext vor allem wegen ihrer Säulen interessiert. Zwei Reihen à I2 Säulen trennen die Schiffe (Abb. 8); sowohl bei den Basen als auch bei den Schäften und Kapitellen handelt es sich um antike Spolien, während die Kämpfer Werkstücke aus dem 5. Jahrhundert sind.39 Bei den Kapitellen handelt es sich um korinthische Kapitelle, die von Friedrich W. Deichmann I969 noch als einheitliche Serie „etwa des beginnenden dritten Jahrhunderts“ deklariert wurden: Zusammen mit den ebenfalls einheitlichen Schäften seien sie „einem ein-

$39 \mathrm{Zu}$ den Kämpfern s. Deichmann 1974, I05-I07; interessant ist, dass die Kämpfer - obwohl ex novo hergestellt - in ihrer Höhe zwischen 38 und $55 \mathrm{~cm}$ oszillieren. zigen römischen Bau (...) entnommen, dessen Abbruch die Kaiserin eigens befohlen haben mag".40 I974 präzisiert Deichmann, dass die Kapitelle zwei Serien angehören und einen „älteren“ und einen „jüngeren“ Typus vertreten: „der ältere Typus gehört sicher noch dem 3. Jahrhundert an, der jüngere könnte gegen dessen Ende entstanden sein. "4i Rita Zanotto schlug jüngst eine nochmals feinere Differenzierung vor, indem sie unter den Vertretern des „älteren“ Typus Stücke erkennt, die bereits dem späten I. Jahrhundert angehören, während sie innerhalb der Gruppe des ,jüngeren“ Typus Stücke sieht, die vielleicht erst im frühen 4 . Jahrhundert entstanden..$^{2}$ Interessant ist die Beobachtung, dass die Vertreter der beiden Typen nicht in einer erkennbaren Ordnung versetzt wurden43; dies dürfte nicht mit Unempfindlichkeit gegenüber dem antiken Prinzip der Einheitlichkeit zusammenhängen,44 sondern damit, dass die vor allem den Stil, nicht aber Form und Motivik betreffenden Unterschiede für den damaligen Architekten kein Unterscheidungsmerkmal darstellten. Ganz offensichtlich hat man versucht, möglichst typähnliche Kapitelle zusammenzutragen; dass man einen einheitlichen Gesamteindruck wünschte, zeigen auch die sekundär überarbeiteten Abakusknäufe, die - falls ihre Überarbeitung tatsächlich im Zusammenhang mit dem Versatz der Kapitelle in der Kirche erfolgte45 - ein Indiz dafür gewertet werden können, dass die Stücke zum Zeitpunkt ihrer Wiederverwendung teilweise bestoßen waren, also nicht aus intakten Gebäuden stammten. Wo sie konkret entnommen wurden, kann aber nicht bestimmt werden. $4^{6}$

Dies gilt auch für die Schäfte der Säulen, bei deren Material es sich vermutlich um Hymettos-Marmor handelt.47 Da in Ravenna in der Spätantike für ex novo hergestellte Schäfte nur prokonnesischer Marmor zum Einsatz kam, ist bereits dadurch ein Hinweis gewonnen, dass es sich bei ihnen um Spolien handeln muss; „Hals- und Fußprofile sowie die Entasis geben ein Datum nicht später als das 3. Jahrhundert" ${ }^{48}$ Auch die Basen dürften Spolien des 3. Jahrhunderts sein, sind aber in sich relativ uneinheitlich und in vielen Fällen stark geflickt.49 Dass die Schäfte der beiden Triumphbogensäulen in Material und Ausma-

40 Deichmann I969, I55. Über das Material der Kapitelle finden sich keinerlei Angaben; es scheint Marmor zu sein.

$4 \mathrm{I}$ Deichmann 1974, I04; vgl. Deichmann 1975, 25. Die Höhe der Kapitelle schwankt zwischen 54,5 und $65 \mathrm{~cm}$.

42 Zanotto Galli I995, 953f.; Novara/Sarasini 200I, 87-89; Zanotto 2007, 92 f. IOI-III mit Tafeln 3-8; Zanotto Galli 2009, 283; Brandenburg 1995, 561 datiert die Kapitelle ins 3. und 4. Jh.

43 Zanotto 2007,47 . 93 f, allerdings mit der Beobachtung, dass die beiden feinsten und lt. Zanotto damit auch 43 Zanotto $2007,47.93 \mathrm{f}$, allerdings mit der Beobachtung, das
ältesten Kapitelle jene sind, die am nächsten zur Apsis liegen.

ältesten Kapitelle jene sind, die am 44 Vgl. Brandenburg I995, $562 \mathrm{f}$.

45 Deichmann I974, 104.

46 Deichmann nahm einen nicht sehr weiten Transportweg, mithin lokale Herkunft an, Zanotto Galli eine Herkunft aus einem Gebäude "dell'ambito Cisalpino", "forse anche della stessa Ravenna"; Deichmann 1975, 26.; Zanotto Galli 1995, 955.

47 Deichmann I974, I04; Zanotto 2007, 99-TOI.

48 Deichmann I.974, I04.

49 Deichmann I974, I03f;; Zanotto 2007, 94-98. 
ßen leicht differieren, dürfte im Bau des 5. Jahrhunderts nicht aufgefallen sein, da sie unter Galla Placidia eine Verkleidung aus Silberblech erhielten..$^{\circ}$

Wieso Galla Placidia für ihre Votivkirche auf Spoliensäulen zurückgriff, wissen wir nicht; Rita Zanotto Galli vermutet, dass die Kaiserin damit ihre Romanitas zur Schau stellen wollte, während Hugo Brandenburg hier schiere Notwendigkeit am Werke sieht, da es offenbar keine lokale Werkstatt gegeben habe, die fähig gewesen sei, zeitgenössische Werkstücke in ausreichender Anzahl herzustellen. ${ }^{\text {I }}$ Nicht zu vergessen ist, dass auch die Kirchengründungen von Ambrosius in Mailand, wo überprüfbar, Spolienstützen besaßen, die ravennatische Johanneskirche also in bester oberitalischer Tradition steht.52

Wie auch immer: Sicher zu erkennen ist in S. Giovanni Evangelista der Wunsch, ein möglichst einheitliches Ensemble zu kreieren, was Galla Placidias Kirchengründung mit den etwa zeitgleichen römischen Kirchen S. Sabina und S. Pietro in Vincoli parallelisieren lässt. 53 Varietas scheint kein ästhetischer Parameter in dieser Zeit gewesen zu sein. Allenfalls wurden einzelne hervorragende Reliefs als Eyecatcher eingesetzt, wie das Beispiel des Türsturzes des sog. Mausoleums der Galla Placidia zeigt.

\section{Ravenna unter Theoderich: Versuch einer Harmonie von Alt und Neu}

Der Wunsch nach Einheitlichkeit zeichnet sich auch in der Palastkirche Theoderichs, heute S. Apollinare Nuovo, ab. Theoderich hatte 493 Odoaker vom Thron gestoßen und selbst den Titel eines Rex Italiae angenommen, unter dem er mehr als 30 Jahre von Ravenna aus regierte. Seiner Residenzstadt ließ er - wie aus Cassiodors Variae ersicht lich - mannigfaltige infrastrukturelle Verbesserungen angedeihen, legte Sumpfregionen trocken, erneuerte die Frischwasserzufuhr und ließ die öffentlichen Bauten restaurieren.

Der Palast, in den er einzog, war jener, in dem bereits Honorius residiert hatte. Unter Valentinian war das Palastquartier durch einen weiteren Palast mit dem Beinamen „ad Laureta" erweitert worden, der bisher jedoch archäologisch nicht lokalisiert ist.54 Zeitgenössische Beschreibungen von Theoderichs Palast lassen einen zumindest groben Ein druck von der Pracht der Anlage und ihrer Ausstattung rekonstruieren; unter anderem is von Säulenportiken die Rede, die den Palast umgaben, sowie von einem bronzenen Reiter-

50 Die entspr. Quellen, die eine Silberverkleidung der Triumphbogensäulen belegen, datieren zwar erst aus dem Mittelalter, doch ist unwahrscheinlich, dass die Veredelung der Säulen erst in nachbyzantinischer Zeit erfolgt ist Deichmann I974, I08. III; vgl. Deichmann I975, 25

5I Brandenburg 1995, 56rf.; Brandenburg 1996, 23f.; Zanotto Galli 2009, 284

52 Mirabella Roberti 1978, 192-20I.

53 Zanotto Galli spricht von einer "discreta omogeneità" und davon, dass es für einen im Schiff stehenden Betrachter schwierig sei, die Unterschiede zu erkennen; Zanotto Galli I995, 955.

54 LPRav Kap. 40; Nauerth 1996, 206 f standbild Theoderichs, das ursprünglich vielleicht den byzantinischen Kaiser Zeno darstellte, also wohl eine Spolie war, die von Theoderich zum Zwecke der eigenen Herrschaftsrepräsentation umgewidmet wurde.55

Agnellus, von dem der Bericht über das Reiterstandbild stammt, gibt auch die zeitgenössische Bezeichnung einiger Palastbereiche wieder, die klar erkennen lassen, dass diese dem Modell des Konstantinopler Kaiserpalastes folgten. ${ }^{6}$ Für die Verschönerung des Palastes hatte Theoderich aber keine Werkstücke aus Konstantinopel importieren lassen, sondern Spolien aus Rom angefordert sowie erfahrene Marmorarbeiter für die Instandsetzung der "basilica Herculis“, die vermutlich Teil des Palastbezirks war.57 Bei den Spolien ging es konkret um „marmora [...] de domo Pinciana“, um deren Übersendung nach Ravenna der Gotenkönig den römischen Patricius Festus anno 507 oder kurz danach bat. $5^{8}$

Allgemein wird angenommen, dass die kostbaren Porphyrverkleidungsplatten, die beiden Alabastersäulchen und die darauf aufsitzenden Serpentinkapitelle aus dem 3. Jahrhundert, die seit dem I6. Jahrhundert vor bzw. in der Capella delle Reliquie in S. Apollinare Nuovo verbaut sind (Abb. 9), aus dem Palast Theoderichs stammen und zur angeforderten Spoliensendung aus Rom gehören könnten. 59 Dies gilt auch für die vier Porphyrsäulchen und die beiden ägyptisierenden Kapitelle aus dem 2. Jahrhundert, die ihre engsten Paralle-

55 LPRav Kap. 94; Nauerth 1996, 356-36I; vgl, unten, Anm. 79. Weitere Quellen zusammengestellt bei Deichmann $1989,5 \mathrm{rf}$.

56 LPRav Kap. 94; Nauerth 1996, 356f. Vgl. auch Deichmann I989, 53-58.

57 Var. I, 6 (anno 507/9): ,... vere dignum est regem aedificiis palatia decorare. absit enim ut ornatui cedamus veterum, qui inpares non sumus beatitudine saeculorum. Quapropter in Ravennati urbe basilicae Herculis amplum opus aggressi, cuius nomini antiquitas congrue tribuit, quicquid in aula praedicabili ammiratione fundavit, magnitudini tuae studiosissime delegamus, ut secundum brevem subter annexum de urbe nobis marmorarios peritissimos destinetis, qui eximie divisa coniugant ...;; MGH Auct. Ant. I2, S. I6f., deutsche Übersetzung bei Dinzelbacher 2010, 79. Zur Spolienverwendung bei Theoderich s. Ward-Perkins 1984, I62. 215-217; Brenk 1987, ro7f.; La Rocca 1993, 466-47I. 479-484; Lachenal I995, 47-56; Coates-Stephens 2003, 354f; Liverani 2004, 424f.; Fauvinet-Ranson 2006, 282-286. Zur "basilica Herculis" s. Dyggve 1956, 34-37; Fauvinet-Ranson 2006, $49-52$.

58 Var. III,IO (507/II); MGH Auct. Ant. I2, S. 84. Vgl. auch Fauvinet-Ranson 2006, 97-I00. Es ist nicht ganz klar, ob der Spolienmarmor nur für den Palast vorgesehen war, wie dies gemeinhin vermutet wird. Theoderich leitet seinen Brief zwar damit ein, dass es sich für Festus gerieme, ales in augendis fabricis reglibus" zur Vefintet seine Bif für Sch zezialisten furr Schwertransporte - vonstatten gehen; zum Begriff "catabolenses" s. Zimmermann i967, 73f. In einem weiteren Brief Theoderichs aus diesen Jahren (507/II), dieses Mal an die Begüterten in Estuni adressiert (Var. III,9; MGH Auct. Ant. I2, S. 84), bittet der Gotenkönig um die antiken „columnas et lapides", die auf dem Gemeindegebiet von Estuni ungenutzt herumlägen und dem Ambiente einen ruinösen Eindruck verleihe, weshalb er anweist, dass besagte "platonias vel columnas" nach Ravenna geschickt würden; wo sie dort eingesetzt werden sollten, wird leider nicht präzisiert. Dasselbe gilt für die Quader („quadrati" ${ }^{4}$ ), die Theoderich $523 / 6$ aus Faenza anforderte; Var. V,8 („Atque ideo ad Faventinam civitatem civilem exsecutionem te praecipimus destinare, ut sine cuiusquam concussione vel damno quadrati ad Ravennatem urbem ex nostra iussione devehantur, quatenus et nostro desiderio gratulemur impleto et querulis vociferandi amputetur occasio"); MGH Auct. Ant. I2, 148); vgl. Fauvinet-Ranson 2006, I42 f. Zur Lokalisierung von Estuni s. Jurlaro 1986, 149 (Vasto in den Abruzzen); Liverani 2004, 424 mit Anm. 188 (Ostuni in Apulien).

59 Deichmann 1974, I38f.; Deichmann 1975, 25; Novara 1998, 27; Novara/Sarasini 200I, 9I-93. 


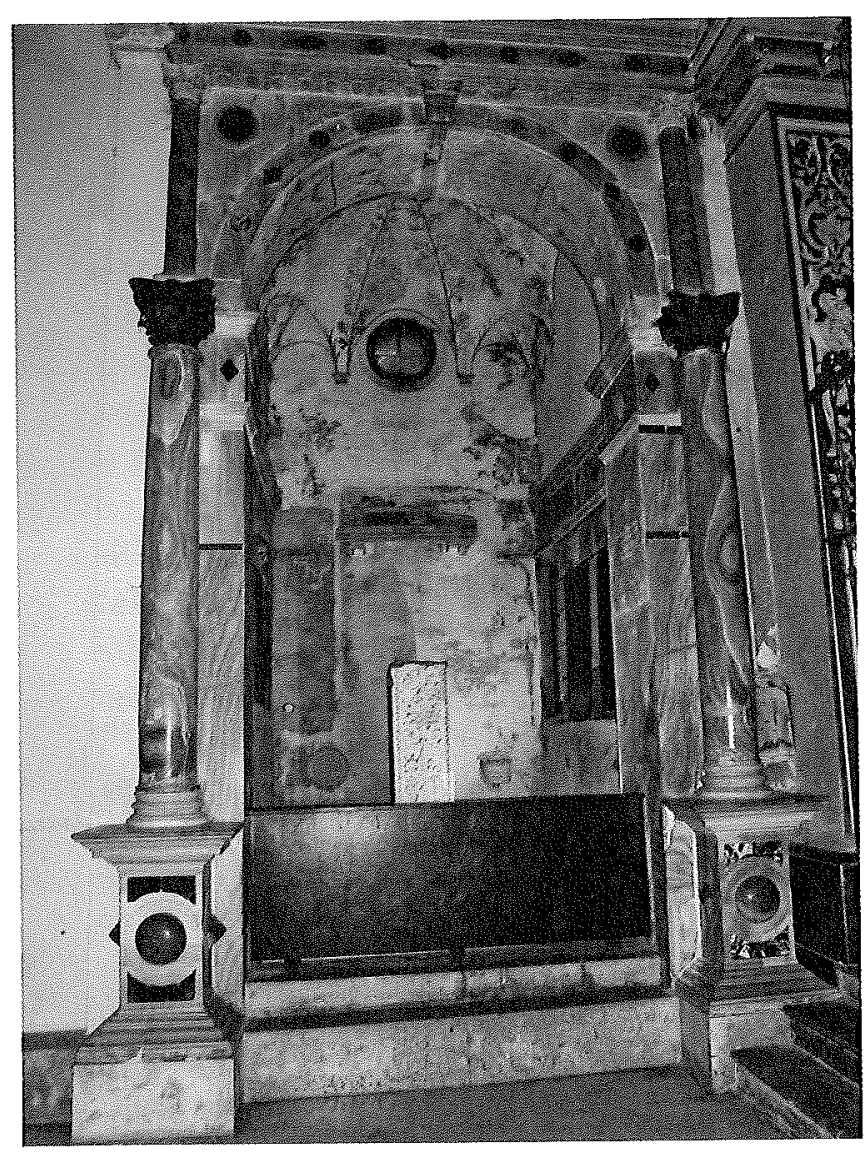

Abb. g| Ravenna, S. Apollinare Nuovo, Capella delle Reliquie: Zugang, von Süden (Foto: C. Jäggi)

len in Rom haben; heute sind sie Teil des Altarziboriums von S. Apollinare Nuovo, doch dürften sie einst den Palastbereich geziert haben. Der antike Marmorthron, der heute in der Apsis der Apollinariskirche steht, könnte ebenfalls aus Rom stammen und für den Palast von Theoderich bestimmt gewesen sein. ${ }^{60}$

Ob Theoderich auch auf ravennatische Spolien zurückgegriffen hat, ist schwer zu entscheiden; der frühkaiserzeitliche Architrav, der sich - im I6. Jahrhundert umgearbeitet zu einem Altarstipes mit Reliquiendepositorium - ebenfalls in der Capella delle Reliquie in S. Apollinare Nuovo befindet (Abb. Io), könnte genauso wie die oben genannten Stücke eine aus Rom importierte Spolie sein, aber auch aus Ravenna selbst stammen. ${ }^{6 \mathrm{I}}$ Die Konsolengeisa hingegen (Abb. II und I2), die von den Baumeistern Theoderichs als Bogenan fänger in S. Apollinare Nuovo verbaut und für diesen Zweck ergänzt wurden, scheinen lo-

60 Deichmann 1974, 139

6I Novara/Sarasini 200I, 95. 100

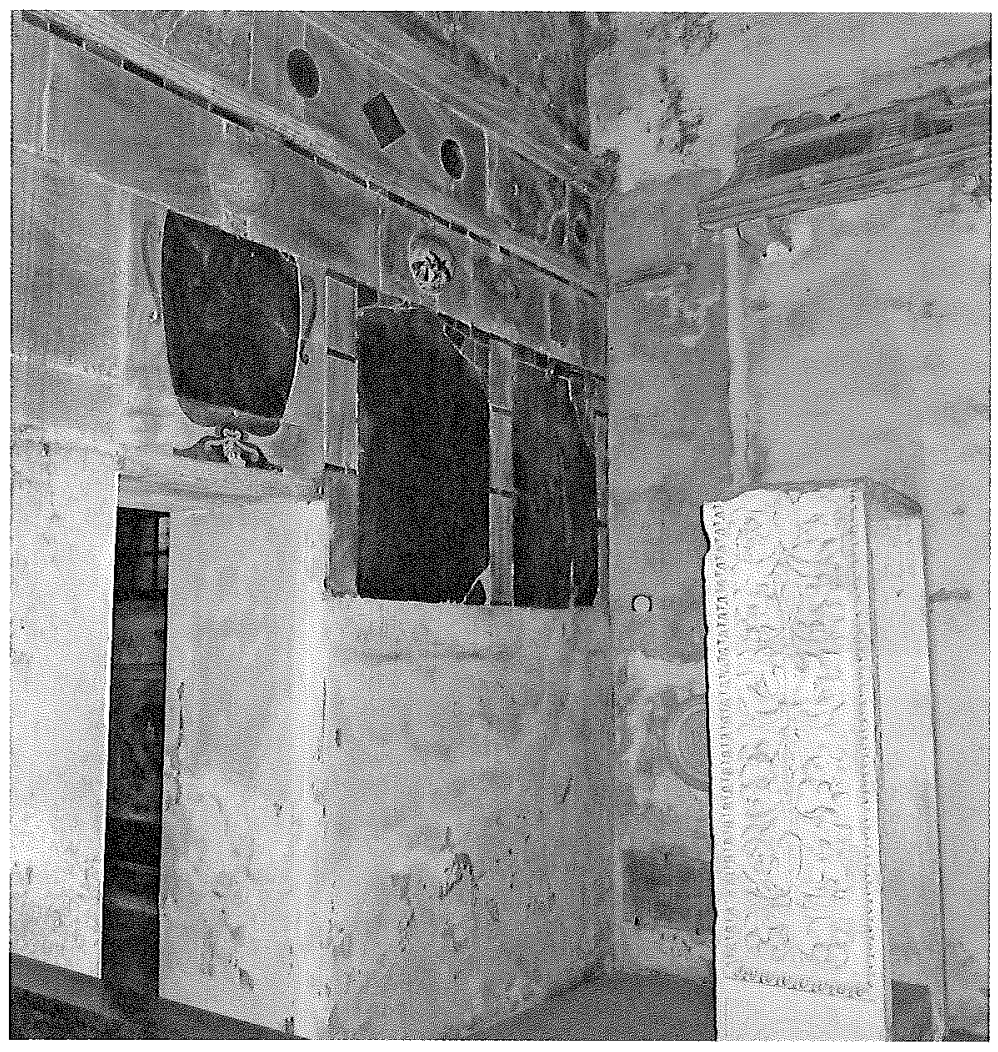

Abb. 10 | Ravenna, S. Apollinare Nuovo, Capella delle Reliquie: Porphyrplatten und frühkaiserzeitlicher Reliefblock, vermutlich aus dem Theoderichpalast stammend (Foto: C. Jäggi)

kale Werkstücke der frühen Kaiserzeit zu sein. ${ }^{62}$ Es sind nota bene die einzigen Spolien, die in Theoderichs Palastkirche Verwendung fanden; alle anderen Werkstücke, insbesondere die Säulen inklusive Kapitelle, Kämpfer und Basen, aber auch der Ambo und die reliefierten Schrankenplatten, sind Importstücke aus des prokonnesischen Marmorwerkstätten. ${ }^{63}$ Theoderich hat demnach für seine Palastkirche, die er dem Salvator weihte, in Konstantinopel beziehungsweise Prokonnesos einen Fertigbausatz angefordert, wie sie für das 6. Jahrhundert dann im ganzen Mittelmeerraum nachgewiesen sind. ${ }^{64}$

$\mathrm{Zu}$ Recht hat insbesondere die jüngere Forschung darauf hingewiesen, dass der Rückgriff auf solche aus weitgehend standardisierten Einzelteilen bestehenden Bausätze am Be-

62 De Maria 2000, 293; Zanotto 2007, II7-I2I. Deichmann I974, I35f. hatte die Stücke in hadrianische Zeit datiert.

63 Deichmann I974, I3i-138. Bei den Mauerziegeln handelt es sich hingegen ausschließlich um Spolien; Righini 1991, I2If.

64 Kapitän I980; Monna/Pensabene/Sodini 1985, 19. 28f.; Pensabene 1989, 46; Harper 1997. 

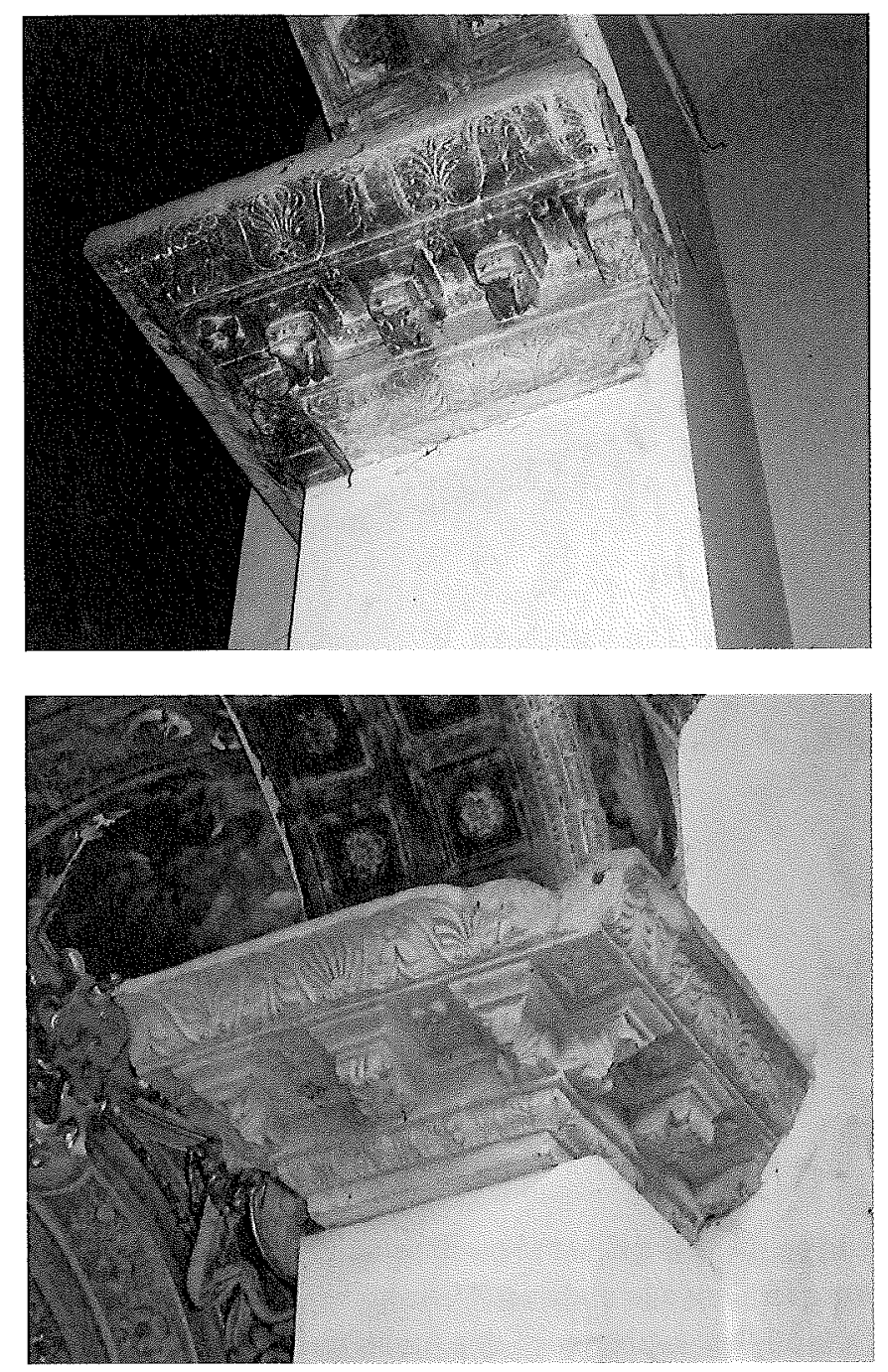

Abb. 11 und $12 \mid$ Ravenna, S. Apollinare Nuovo: als Bogenanfänger wiederverwendete Konsolengeisa des I. Jhs. n. Chr. (Fotos: C. Jäggi)

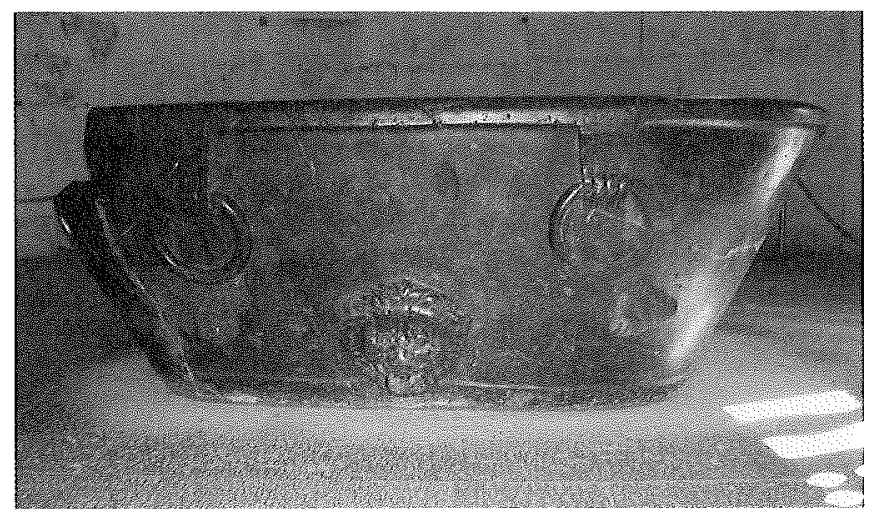

Abb. 13| Ravenna, Mausoleum des Theoderich, Porphyrwanne

vermutlich des 4. Jhs. n. Chr., von Theoderich als Sarkophag umgenutzt (Foto: C. Jäggi)

stimmungsort von den ortsansässigen Bauhandwerkern eine ähnliche Flexibilität erforderte wie der Einsatz von Spolien; ${ }^{65}$ so scheint man auch im Falle der ravennatischen Salvatorkirche erst während des Versatzes gemerkt zu haben, dass das Problem der Bogenanfänger mit dem angelieferten Material nicht gelöst werden konnte, und eine ad hocLösung mittels Spolien gefunden.

Die einzige andere Spolie, die in einem "Sakralbau“ Theoderichs zum Einsatz kam, ist die antike Porphyrwanne, in der Theoderich nach seinem Tod im Jahre 526 bestattet wurde (Abb. I3); für das zugehörige Mausoleum hingegen wurde Istrischer Kalkstein verwendet, der insbesondere durch seine hochraffinierte Versatztechnik nicht minder kostbar wirkt wie Marmor. ${ }^{66}$

Dass die Porphyrwanne eine klare imperiale Symbolik besitzt, die durch kein anderes Material vermittelt werden konnte, braucht nicht eigens betont zu werden. Genauso waren auch die aus Rom importierten Spolien politisch konnotiert, was nicht zuletzt daran erkennbar wird, dass Theoderich diese Stücke ausschließlich für seinen Palast vorsah, nicht aber für seine Kirchenbauten. ${ }^{67}$ Die Tatsache, dass die Stücke aus Rom aus einem ruinösen Gebäude entnommen werden sollten, das nicht mehr instand gestellt werden konnte, tut

65 Brandenburg 2007/8, 188; Bauer 2009, 64 f. Vgl. bereits Esch 1969, 13 und Deichmann 1975, 97. Interessant ist, dass auch die als Serie aus Prokonnesos bezogenen Kapitelle in S. Apollinare Nuovo keineswegs identische Maße haben, sondern in ihrer Höhe zwischen 44 und $53 \mathrm{~cm}$ variieren; Deichmann 1974 Iz2f. Strukturell zu vergleichen ist auch die Verwendung von Werkstücken aus Baustofflagern, wie dies in der letzten Zeit mehrfach nachgewiesen werden konnte; Bosmann 2004, Bosmann 2009, Brandenburg $2007 / 8$

66 Zur Porphyrwanne s. Ambrogi 1995, I09-III; Zanotto 2007, 60. 143. Zum Mausoleum als solches s. Deichmann 210-239 und Heidenreich/Johannes I97I.

67 Dazu Brenk 1987, I07-rog; Coates-Stephens 2003, 354f,; Liverani 2004, 424 f. 


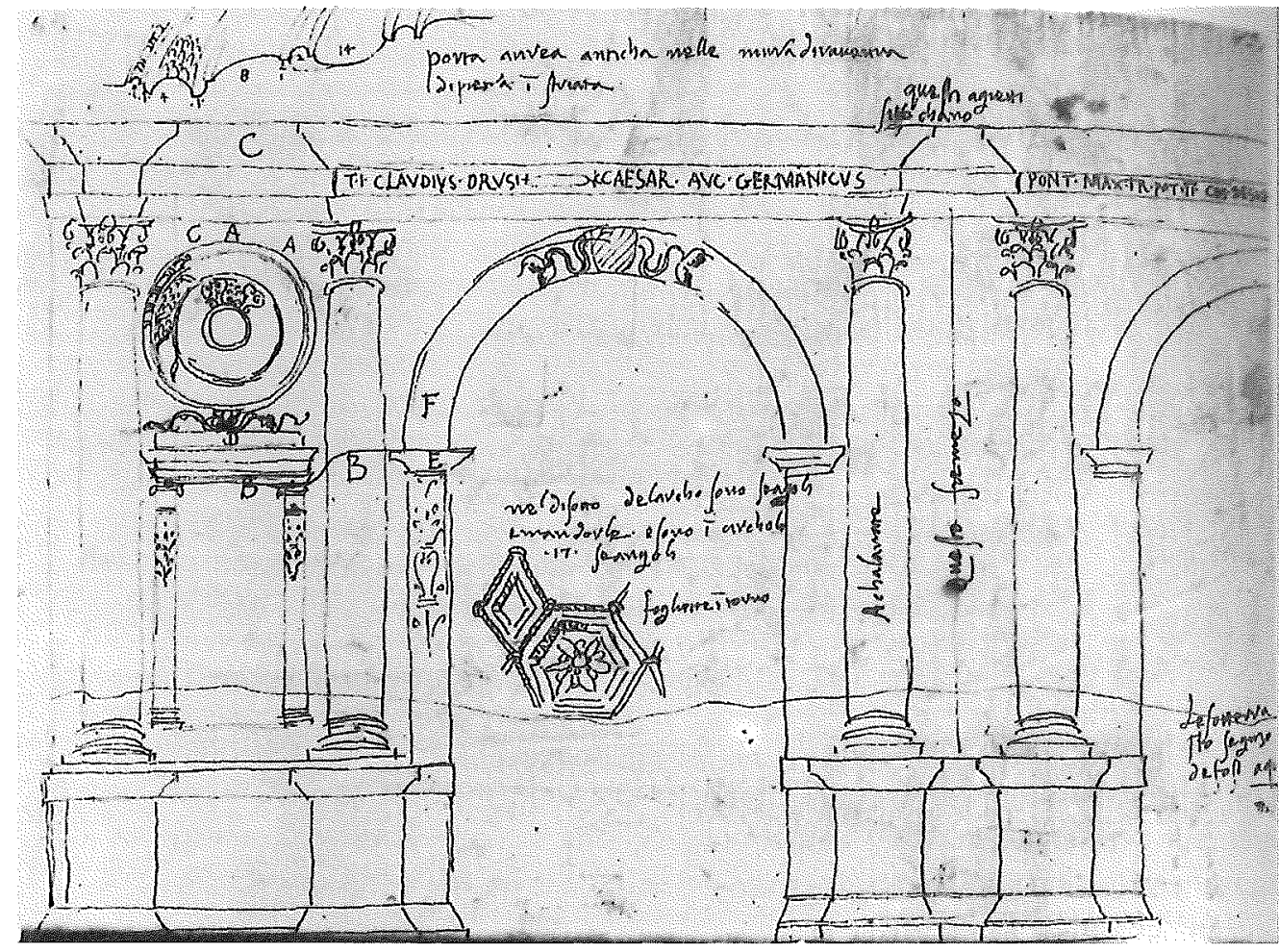

Abb. 14 | Ravenna, Porta Aurea: Zeichnung von Giovanni Battista da Sangallo (Florenz, Uff. Arch. I314) (aus: Felix Ravenna ser. IV, Vol. CXXXIII-CXXXIV, fasc. I/2, I987, S. 92 Abb. 2)

dieser Interpretation keinen Abbruch. Andererseits kann der weitgehende Verzicht Theoderichs auf die Verwendung lokaler Spolien als Hinweis auf seine auch anderswo zu fassenden Bemühungen gewertet werden, das Überkommene $z u$ bewahren und instand $z u$ stellen ${ }^{68}$; ganz offensichtlich lag auch in Ravenna das Hauptinteresse Theoderichs darin, in einer blühenden Stadt zu residieren, wo Altbauten gleichberechtigt neben Neubauten standen und sich nur durch ihr Alter, nicht aber durch ihren "Glanz" von jenen unterscheiden sollten, weshalb Spoliierungen wo immer möglich zu vermeiden waren. Zeigt nicht auch die Tatsache, dass die Porta Aurea, das unter Claudius im Jahre 43 n. Chr. errichtete Südtor Ravennas, bis ins I3. Jahrhundert weitestgehend intakt war, ja in ihrer unteren Zone noch bis zu ihrem Abbruch im Jahre 1582 ihren ursprünglichen Säulen- und Reliefschmuck besaß (Abb. I4), dass bis weit ins Mittelalter hinein die Intaktheit des Stadtbildes

68 Var. III, 9: "nova construere, sed amplius vetusta servare"; MGH Auct. Ant. I2, 84. Zu Theoderichs denkmalschützerischen Aktivitäten s. Zanotto Galli 1995, 958. Siehe dazu auch Johnson I988; La Rocca I993; Meier moor. ein Anliegen der Stadtoberen war und die antiken Monumente in diesem Bestreben eine große Rolle spielten?69

\section{Ravenna in byzantinischer Zeit: Keine Spolien weit und breit}

Der Verzicht auf Spolien charakterisiert auch jene Kirchen Ravennas, die in den $540 e r$ Jahren fertiggestellt wurden, als große Teile Italiens und mit diesen auch Ravenna von den Byzantinern „rückerobert" worden waren. Ravenna war nun Sitz eines oströmischen Statthalters, unterstützt durch den Bischof, der gerade in justinianischer Zeit seine Machtbefugnisse auf Kosten Roms massiv auszubauen verstand und für Ravenna die Erzbischofswürde erwarb.

Offensichtlichstes Dokument dieses neuen Selbstverständnisses ist S. Apollinare in Classe, eine dreischiffige Basilika, die als ravennatisches Gegenstück zur römischen Peterskirche inszeniert wurde; für ihre Stützen wurden allerdings keine Spolien verwendet sondern ausschließlich Werkstücke aus Prokonnesos.7०

S. Apollinare in Classe wurde 548 von Bischof Maximian geweiht, ein Jahr nach der Weihe von S. Vitale, dem hochaparten Zentralbau, der bereits unter Maximians Vorgängern Ecclesius (522-532) und Victor (537-544) ins Werk gesetzt worden war. Auch hier, in der Vitalis-Kirche, sind alle Säulen, Kapitelle, Basen, Transennen etc. Importstücke aus den prokonnesischen Werkstätten; einzig bei den kleinen Pilasterkapitellen aus Serpentin in der Wandverlleidung der Apsis, die freilich in weiten Teilen ein Produlkt der Restaurierungen des frühen 2o. Jahrhunderts ist, wird eine spoliale Verwendung angenommen. ${ }^{7 \mathrm{I}}$ Im Vorchor finden sich zudem zwei in die Seitenwände vermauerte antike Reliefs (Abb. I5), die leere Throne und spielende Eroten zeigen und von jenen Säulchen aus kostbarem Gestein flankiert werden, die bis ins I6. Jahrhundert das Altarziborium trugen und bei den Zeitgenossen höchste Bewunderung hervorriefen. ${ }^{72}$ Die Reliefs datieren aus der I. Hälfte des I. Jahrhunderts n. Chr. und könnten einst ein Monument des römischen Ravenna - vielleicht eine Ara Gentis Juliae nach stadtrömischem Vorbild - geziert haben, doch ist diese Provenienz nicht gesichert, so wie auch unsicher ist, seit wann sich die Stücke überhaupt in der Vitalis-Kirche befinden; diese wurde in der frühen Neuzeit geradezu ein Sammelbecken für Kuriosa und Antiquitäten, so dass nicht ausgeschlossen ist, dass die Reliefs erst im $\mathrm{I} 6$. Jahrhundert in die Kirche gelangten und dort dekorativ verbaut wurden.73

69 Zur Porta Aurea s. Kähler 1935; Rosi 1939; Deichmann I989, 26; Manzelli 2000, 9I-94. Siehe auch unten S. 3I 8 .

70 Deichmann I976, 24I-244. Den Verzicht auf Spolien charakterisiert auch die frühbyzantinische Architektur Konstantinopels; Deichmann I975, 89-9I.

7I Zanotto 2007, I47f

72 Rubeus I590, I59. Zu den Reliefs s. Zanotto 2007, I44-I49; Beschi 1984/5, 37-40

73 Novara 1998,24 , Beschi $2003,203,208 \mathrm{f}$. Weitere Fxemplare dersellen Bildthematik finden sich im Museo Arcivescovile in Ravenna: Lippolis 2000, 266 und De Maria 2000, 305 Kat. 7I. 


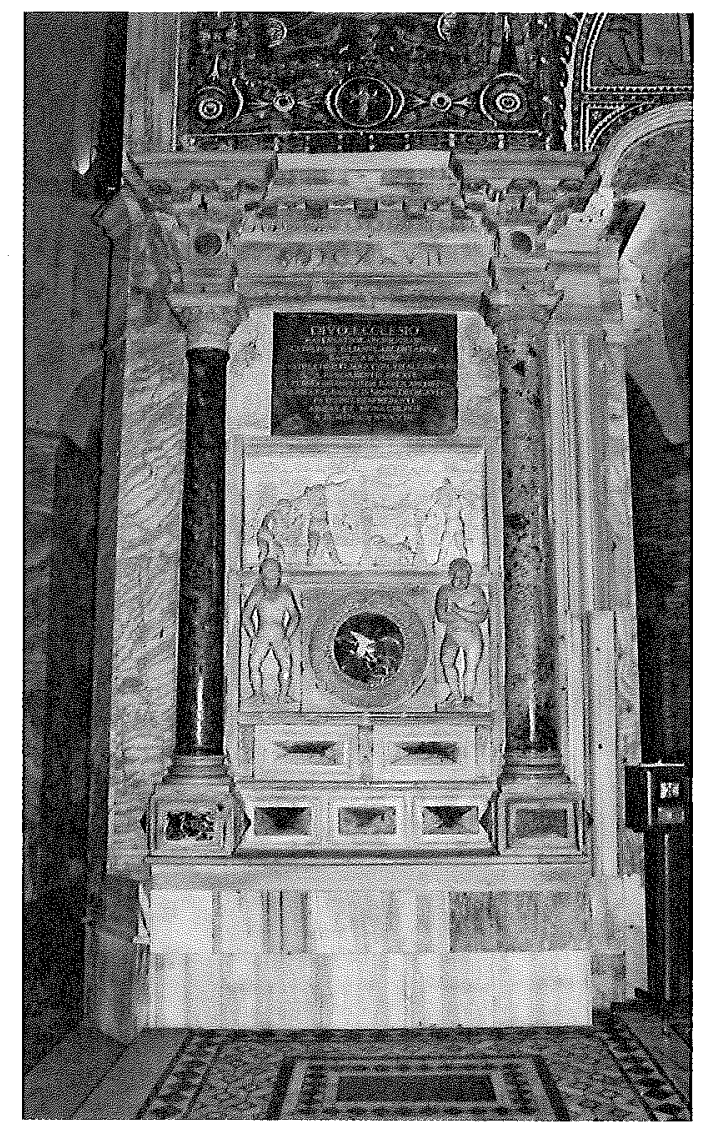

Abb. 15 | Ravenna, S. Vitale, südliche Vorchorwand: Frühkaiserzeitliches Relief, flankiert von den ehem. Ziboriumssäulchen (Foto: C. Jäggi)

\section{Translatio Imperii? Ravenna in karolingischer Zeit}

In Hinblick auf die Spolienthematik rückt Ravenna erst wieder in karolingischer Zeit ins Licht der Geschichte, und zwar durch Karl den Großen.74 Dieser bat um 787 Papst Hadrian, ihm in Hinblick auf seine in Aachen entstehende Pfalzkapelle „Mosaiken, Marmor und Skulpturen (exempla)" aus dem ravennatischen palatium zu überlassen.75 In seiner

74 Ein interessanter Fall, der ca. 50 Jahre vor der Zeit Karls liegt, hier aber nicht weiter ausgebreitet werden soll sind die sechs Spiralsäulen aus Onyx (,columnas VI onichinas volutiles"), die der ravennatische Exarch Eutychio Papst Gregor III. (73I-74I) für St. Peter schenkte; LP Vita Gregorii III (ed. Duchesne I886, 4I7). Ob sie aus Ravenna kamen oder von Eutychios aus Griechenland bzw. Konstantinopel vermittelt wurden, ist nicht bekannt. 75 Zu rekonstruieren ist der Vorgang nur auf der Basis des päpstlichen Antwortschreibens, aus dem hervorgeht, dass der Wunsch Karls dem Papst durch den dux Arvinus vorgetragen worden war; MGH Epp. III, Berlin 1892 S. 6I4, Ep. 8r: „In quibus referebatur, quod palatii Ravennate civitatis mosivo atque marmores ceterisque exemplis tam in strato quamque in parietibus sitis vobis tribuissemus. "Vgl. Story et alii 2005, I88f. Dass Mosaiken tatsächlich wiederverwendet wurden, zeigt ein Bodenfund in S. Quattro Coronati in Rom; Pugliese 2008, 332f.

Vita Karoli Magni präzisiert Einhard, dass Karl sich deshalb unter anderem um Spolien aus Ravenna bemüht habe, weil er vergleichbares Material von anderswoher nicht bekommen konnte. ${ }^{6}$ Papst Hadrian jedenfalls bewilligte den Spolientransfer, doch bleibt im Einzelnen unklar, welche der in der Aachener Pfalzkapelle verbauten „marmora“ tatsächlich aus Ravenna stammen.77 Dasselbe gilt für die karlische Pfalz in Ingelheim, für deren Marmorsäulen ebenfalls eine Herkunft aus Rom und Ravenna überliefert ist. ${ }^{78}$

Von Agnellus wiederum wissen wir, dass Karl auch ein Auge auf das vergoldete Reiterstandbild geworfen hatte, das vor dem Palast Theoderichs stand und den Rex Italiae mit Schild und Lanze darstellte, ursprünglich aber vielleicht ein Bildnis Kaiser Zenos war.79 Karl soll es - wohl unmittelbar nach seiner unter anderem über Ravenna führenden Rückreise von der Kaiserkrönung in Rom anno 800 - über die Alpen transportiert und vor seinem Palast $\mathrm{zu}$ Aachen aufgestellt haben. ${ }^{80}$ Ein weiteres Bronzestandbild Theoderichs scheint bereits 50 oder 60 Jahre zuvor vom Langobardenkönig Liutprand (712-744) oder seinem Nachfolger Aistulf (749-756) aus Ravenna entführt und in die langobardische Königsstadt Pavia überführt worden sein, wo es - als sogenannter Regisole - später zum Stadtsymbol wurde. ${ }^{8 \mathrm{r}}$

Karls Begehrlichkeit fiel in Ravenna außerdem auf eine mit kostbaren Steinen verzierte Krone, ein Geschenk des byzantinischen Kaisers Philippikos (7II-7I3) an die ravennatische Kirche, deren Preis ein jüdischer Händler aber so hoch veranschlagte, dass offenbar kein Handel zustande kam. ${ }^{82}$

76 Vita Karoli Magni Kap. 26, MGH rer. Germ. 25, Hannover/Leipzig I9II, S. 3I: „Ad cuius (i.e. basilicae Aquisgrani) structuram cum col

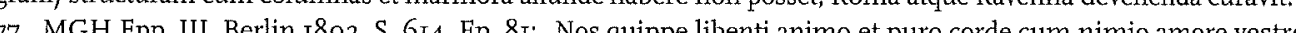
77 MGH excellentlae tibumus effectum et an marmores quamque mostvo ceterisque exemplis de eodem palatio vobis concedimus abstollendum (...)". Zur Herkunftsproblematik der in der Aachener Pfalzkapelle verbauten Spolien s. zuletzt Müller 2009, 194-198

78 Vgl. den Poeta Saxo zum Jahr 8I4; MGH SS I, Hannover 1826, S. 274f. (,Ingylemhem dictus locus est, ubi condidit aulam (...). Ad quae marmoreas praestabat Roma columnas, quasdam praecipuas pulcra Ravenna dedit.") $\mathrm{Zu}$ den Spolien in Ingelheim s. Meckseper 200I, 376.

79 LPRav Kap. 94; Nauerth 1996, 356-36I: ,Vor ihrem Angesicht war ein Sockel, der aus viereckigen zweischichtigen Steinen bestand und sechs Ellen hoch war, darauf aber befand sich das Pferd aus Erz, das mit blinkendem Gold überzogen war. Sein Reiter, der König Theoderich, hielt mit dem linken Arm den Schild, in der erhobenen Rechten die Lanze. Aus den geöffneten Nüstern und dem Maul des Pferdes flogen Vögel heraus und bauten ihre Nester unter seinem Bauch. Kann sich jemand ein solches Denkmal vorstellen? Wer mir nicht glauben will, gehe Nestron will, gehe Aner Zeno geschaffen worden sei, (...) Fu ihn wurde jenes außerordent che

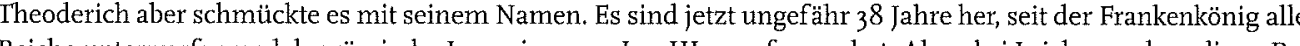
Reiche unterworfen und das römische Imperium von Leo III. empfangen hat. Als er bei Leichnam des seligen Petrus den Treueid geleistet hatte, kehrte er wieder ins Frankenreich zurück. Dabei kam er nach Ravenna und sah das herrliche Bild, von der er selbst bezeugt, dass er niemals etwas Vergleichbares gesehen hat. Er sah es, ließ es ins Frankenreich transportieren und in seinem Palast in Aachen aufstellen. " Zuletzt dazu: Hammer 2005, 309-318. 80 Das geht nicht nur aus Agnellus' Liber Pontificalis, sondern auch aus einem Gedicht von Walahfrid Strabo von 829 hervor; Thürlemann I977, 38-63.

81 Ricci r989, 540; Saletti I997.

82 LPRav Kap. 143; Nauerth $1996,512-515$. 
In Karls Spoliierung Ravennas wird in der Regel ein klarer politischer Impetus gesehen, auch wenn dies durch keine Schriftquelle explizit zu belegen ist. ${ }^{8} 3$ Dass Karl auf seiner Suche nach kostbarem Baumaterial nicht nur Rom, sondern auch Ravenna im Blick hatte, dürfte damit zusammenhängen, dass Ravenna - noch vor Rom - vom frühen 5. bis ins mittlere 8. Jahrhundert das politische Zentrum Italiens war.

Gerne wüsste man, in welchem Zustand der ravennatische Palast war, als Papst Hadrian ihn zur Spoliierung freigab. Das letzte Dokument, das den ravennatischen Palast als in Funktion stehend ausweist, ist eine Urkunde des Langobardenkönigs Aistulf vom 4. Juli $75{ }^{1}{ }^{84} \mathrm{Als}$ Aistulf fünf Jahre später vom Frankenkönig Pippin aus Ravenna vertrieben wurde und das ehemalige Exarchat an den $\mathrm{Hl}$. Stuhl in Rom überging, bedeutete dies das Ende des ravennatischen palatium; es wurde fortan nicht mehr benutzt und wenige Jahre später vermutlich gezielt zerstört. ${ }^{85}$ Es ist bestechend, mit Paolo Verzone anzunehmen, dass Karls Bitte um Spolien aus dem ravennatischen Palast und die bereitwillige Gewährung der Bitte seitens des Papstes den Willen der beiden Potentaten dokumentierte, Ravenna als Machtzentrum ein für alle Male von der politischen Landkarte zu löschen. ${ }^{86}$ Verzone glaubt, dass die päpstliche Erlaubnis als bewusster Schlag gegen die Autonomiebestrebungen der ravennatischen Erzbischöfe verstanden werden muss, die sich nach dem Ende der byzantinischen Herrschaft in Ravenna zusehends zu den Sachwaltern und Erben der Exarchen stilisiert hatten. ${ }^{87}$

Die Spoliierung des ravennatischen Palastes hatte somit einen eminent symbolischen Charakter, da damit materiell dokumentiert wurde, dass sich hier keine Macht mehr niederlassen sollte; diese saß nun an einem anderen Ort und regierte von dort aus die Geschicke Ravennas. Ravenna verblieb jedoch der Ruhm einer einstigen Kaiser- und Königsresidenz, die nicht nur für die Karolinger, sondern später auch für die Ottonen einen hohen symbolischen Wert besaß; nur so ist es zu erklären, dass durch Ludwig den Frommen kurz nach 8I4 ein mit einer Vedute der Stadt Rom verzierter Silbertisch aus dem Erbe Karls des Großen an die ravennatische Bischofskirche geschenkt wurde, zusammen mit kostbaren liturgischen Gefäßen. ${ }^{88}$ Auch für die Ottonen sind enge Beziehungen zu Ravenna überliefert; ob allerdings die beiden frühbyzantinischen Kämpferkapitelle im

83 Esch 1969, 50 f.; Brenk 1987, ro8f.; Lachenal r995, 109-128; Fabricius Hansen 2003, I57-I60; Greenhalgh 2009, 338-340; Müller 2009, 194-198. Kritisch - unter Hinweis auf die fehlenden Schriftquellen - Binding $2007,18-28$.

84 Fantuzzi 1803, 203f. Nr. VIII.

85 Dass das Palatium zur Zeit Karls nicht mehr funktionstüchtig war, zeigt auch die Tatsache, dass Karl auf seiner Reise durch Ravenna im Bischofspalast gastierte; LPRav $1996,567 \mathrm{f}$

ner Reise durch Ravenna in
86 Verzone $1962,78 f$.

86 Verzone 1962, $78 \mathrm{f}$.
87 Verzone 1962,77 f., Ricci 1989, 539 (unter Hinweis darauf, dass bspw. Erzbischof Leo (770-777) für sich den Titel "Italiae exarchus" verwendete). Vielleicht muss bereits Agnellus' Erzählung, wonach Papst Stephan II. (752-757) den ravennatischen Zwischenhalt auf seiner Reise zu König Pippin dazu benutzt habe, sich am ravennatischen Kathedralschatz zu vergreifen und den Großteil davon ins Frankenland geschickt habe, als Machtgeste des Papstes gegenüber dem ravennatischen Bischof verstanden werden; Kap. I58; Nauerth 1996, 548-554.

88 Kap. 170; Nauerth I996, 584f. Dieser Tisch wird - zusammen mit zwei ähnlichen Tischen - auch in der Vita Caroli Magni von Einhard (Kap. 33) erwähnt; MGH rer. Germ. 25, Hannover/Leipzig I9II, 40.
Remter am Magdeburger Domkreuzgang, die im Zuge von Ottos des Großen Spolienim port aus Italien nach Magdeburg gelangt sein dürften, aus Ravenna stammen, wie dies verschiedentlich angenommen wird, kann nicht entschieden werden, da die Stücke einen im 6. Jahrhundert weitverbreiteten Typus vertreten, der im ganzen nordadriatischen Raum belegt ist. 89

Einen weiteren erhellenden Einblick in die karolingische Spolienpraxis und -wahrneh mung in Ravenna bietet Agnellus' Bischofschronik aus dem vierten Jahrzehnt des 9. Jahrhunderts. Mehrfach spricht der Chronist davon, dass zu seiner Zeit Sarkophage von Zweitnutzern requiriert wurden und in dem Zusammenhang auch die Stadt verlassen konnten. So soll etwa Bischof Theodor von Bologna den Sarkophag von Rufus und seiner Tochter, die vom hl. Apollinaris vom Tode auferweckt worden war, aus Ravenna weggeholt „und in seine Kirche in Bologna gebracht (haben), um nach seinem Tod selbst darin bestattet zu werden"9o, und den diaphanen Sarkophag des Lauricius im „monasterium Gervasii et Protasii" bei S. Lorenzo soll später angeblich ein Kaiser wiederverwendet haben.9"

Voller Trauer berichtet Agnellus zudem von der Entnahme einer besonders kostbaren Porphyr- beziehungsweise Alabasterplatte in S. Apollinare in Classe für Kaiser Lothar, bei der er selbst zu assistieren hatte; die durchscheinende Platte, auf der man, „wenn die Türen, die auf die Kirche des seligen Severus hinausgehen, offenstanden, [...] Menschen, Tiere, Vögel und alle möglichen Dinge dahinziehen sah wie (auf) einem Spiegel“, wurde im Auftrag des Bischofs entfernt, wobei dieser niemanden anderen als Agnellus damit beauftragte, die Extraktion zu beaufsichtigen, „damit die Handwerker behutsam mit der edlen Platte umgingen und sie nicht zerbreche"..$^{2}$ Kaiser Lothar ließ die Platte - so berichtet Agnellus weiter - „in einen hölzernen, mit Wolle ausgelegten Behälter einschließen und ins Frankenland bringen", wo sie seither als Altarmensa diene.93 Agnellus nahm dieser „Kunstraub" so mit, dass er seinen Aufsichtsposten verlassen und sich zurückziehen musste.94 Allerdings scheint er wenige Jahre später selbst Spolien in großem Stil verwendet $z u$ haben, wenn auch aus einem vermutlich aufgelassenen Bau. Freimütig erzählt er, wie er seinen Dienern befohlen habe, jenen „ziemlich großen Pa-

89 Meckseper 200I, 370-372; Forster 2009.

90 Kap. I; Nauerth I996, 98f. Das Ereignis kann durch die Angabe, dass sich der Vorfall etwa „vor fünf Jahren“ ereignet habe, in die Zeit um $825 / 30$ datiert werden. Aus Agnellus geht ferner hervor, dass die Bestattung des Bischofs in dem von ihm requirierten Sarkophag schließlich doch nicht zustande kam.

9I Kap. 36; Nauerth I996, 178-I8I. Vgl. LPRav Kap. 97; Nauerth 1996, 376f., wo berichtet wird, dass der Sarkophag von Bischof Petrus dem Älteren aus seinem urspr. Aufstellungsort neben der Eufemia-Kirche in Classe herausgerissen und an einem anderen Ort wieder aufgestellt worden sei.

92 Kap. II3; Nauerth $1996,420-423$.

93 Ebd.; es wird in diesem Zusammenhang berichtet, dass die Platte im Frankenreich als Altarmensa in einer dem hl. Sebastian geweihten Kirche wiederverwendet wurde.

94 Kap. II3; Nauerth I996, 422 f. „Mein Herz aber war so traurig darüber, dass ich mich anderswohin zurückzog." 
last" abzureißen, den sich einst Theoderich „auf einer Insel nahe der Meeresküste“, unweit von Ravenna, „beim sechsten Meilenstein“ hatte errichten lassen.95 In der ehemaligen Badeanlage hatte sich offenbar im Laufe des Frühmittelalters ein Kloster eingenistet (S. Maria in Palazzolo), während der ehemalige Palast zu Agnellus' Zeiten nicht mehr in Nutzung gewesen zu sein scheint. ${ }^{6}$ Agnellus, nota bene Mitglied des Kathedralklerus, ließ das Baumaterial nach Ravenna schaffen und baute damit sein Haus, das im Zentrum der Stadt neben der Kirche der hl. Agnes stand; dieses heiße - so präzisiert Agnellus - „domus presbiterialis“, woraus gefolgert werden kann, dass es eine Art Amtssitz war und sich vermutlich auf kirchlichem Grund erhob.97 Dass Agnellus dafür Hand an einen ehemaligen Königspalast legen konnte, spricht dafür, dass auch dieser damals im Besitz der Kirche war.

\section{Spoliierung als Bestrafung: Ravenna unter Friedrich II.}

Im I3. Jahrhundert verdichten sich dann die Nachrichten, wie sich die weitere Spoliierung Ravennas gestaltete. So ist der chronikalischen Überlieferung zu entnehmen, dass Kaiser Friedrich II. anno I24I im Zuge der politischen Auseinandersetzungen in Oberitalien Ravenna für seine propäpstliche Parteinahme unter anderem mit dem Teilabriss der Porta Aurea bestrafte.$^{8}$ Allerdings besteht Unklarheit darüber, ob Friedrich die Marmordekoration des römischen Prunktores in den Kalkofen befördern ließ - laut Arnold Esch „die fürchterlichste Transsubstantiation des antiken Monuments" 99 - und den damit gebrannten Kalk für eine Neubefestigung der Stadtmauern verwendete oder aber die antiken Zierelemente mit dem Schiff von Rimini aus nach Palermo verschickte. ${ }^{\circ 00}$ Den Weg nach Sizilien scheinen auf jeden Fall einige Säulen aus S. Vitale genommen zu haben sowie eine marmorne Brunnenfassung, die aus dem erzbischöflichen Palast stammte. ${ }^{\text {Ior }}$ Auch bei die-

95 LPRav Kap. 39; Nauerth 1996 , 198f.

96 Zum ehem. Palast des Theoderich in Porte Lione/Palatiolum s. Bermond Montanari 1983.

97 LPRav Kap. 39; Nauerth 1996, 198-201. Aus dieser Passage geht auch hervor, dass es auf der einen Seite an die Agneskirche grenzte.

98 Crosara I952, 279; Greenhalgh 2009, I51.

99 Esch I969, 6; vgl. ebd. 3 I.

Ioo Vgl. die Chronica de civitate Ravennae aus dem I4. Jh., abgedruckt in: Spicilegium Ravennatis historiae, a cura

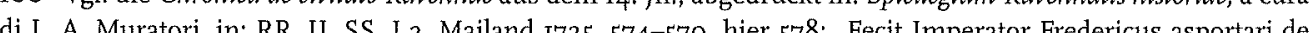
(1)

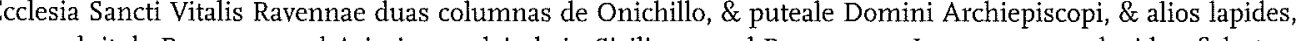
quos voluit de Ravenna apud Ariminum, deinde in Siciliam apud Panormum. Insuper omnes lapides, \& lastras marmoreas de Porta Aurea, quaecumque inventae sunt, ad calcinariam, ac ex eis facta est calcina pro Castris Imperatoris aedificatis in muro circa murum Ravennae." Anders Rubeus 1590 , 418 : „Portam quoq. auream, quam Triumphalem, ob Claudii Caesaris triumphum, appellabant, admirabili lapidum, ac gemmarum ornatu spoliauit, nauiq. Liburnica, Arimino Panormum Siciliae urbem, eodem anno transuexit."

IOI Siehe Anm. I00. Vgl, Rubeus I590, 418: „Ex aede autem D. Vitalis, columnas ex marmore praestanti complures, \& Archiepiscopale marmoreum puteal, multosq. praeterea nobilissimos lapides, \& praeclara ornamenta Ariminum inuexit."

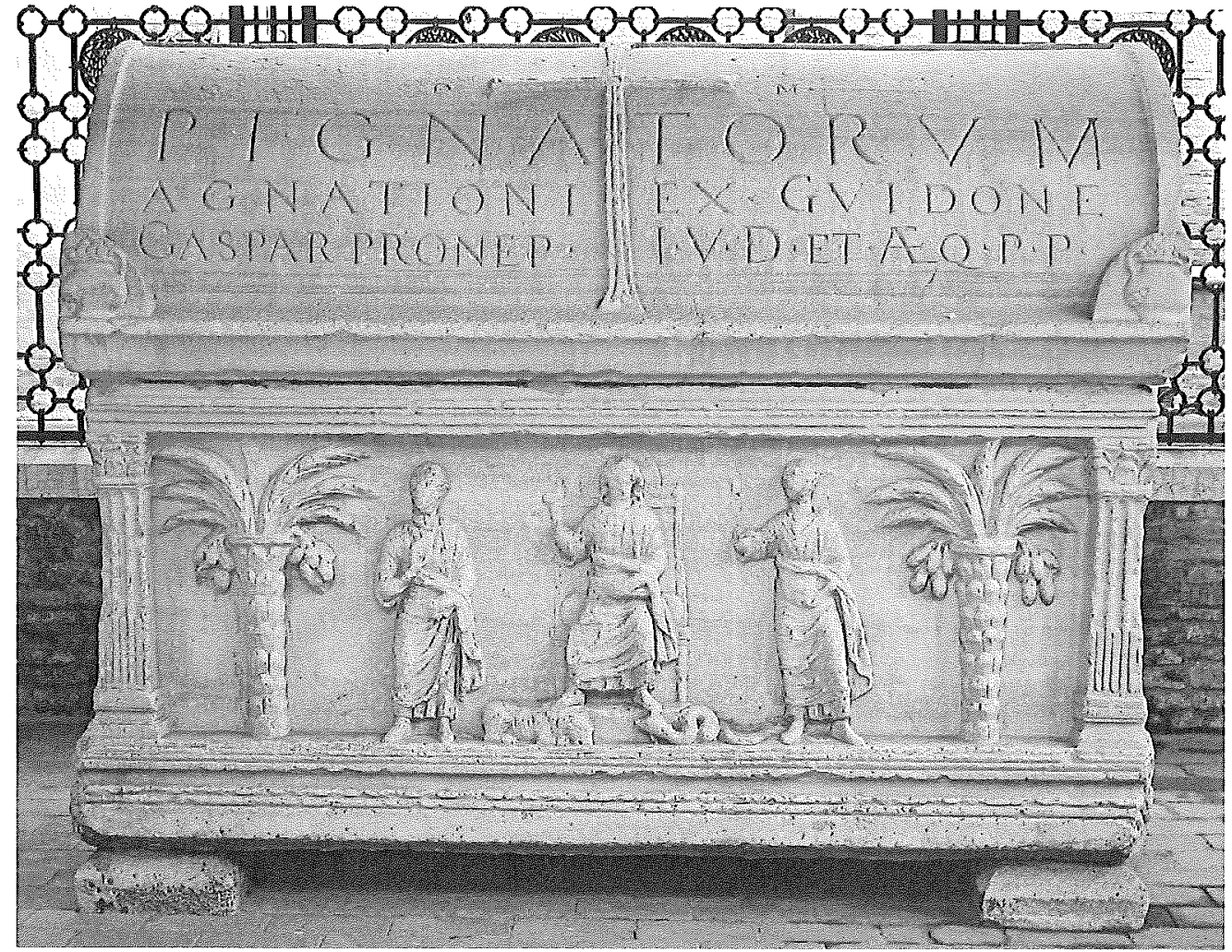

Abb. 16 | Ravenna, Sarkophag aus der Zeit um 400 im sog. Braccioforte beim Dante-Grabmal; im I6. Jh. von der Familie Pignati als Grablege wieder verwendet (Foto: C. Jäggi)

sem Transport wird Rimini als Verladehafen genannt, was zeigt, dass Ravenna beziehungsweise Classe damals nicht mehr schiffbar waren.

\section{Spolien als Antiquitäten: Ravenna im 13. und 14. Jahrhundert}

Ins 13. Jahrhundert fällt aber nicht nur die Strafexpedition Friedrichs II. gegen Ravenna, sondern auch eine Welle der Wiederverwendung spätantiker Prunksarkophage für die Bestattung von kirchlichen und laikalen Würdenträgern. Etliche ravennatische Sarkophage des 5. und 6. Jahrhunderts gelangten in diesem Zusammenhang nach Ferrara und in andere oberitalienische Städte, wurden jedoch auch in Ravenna selbst als Leichenbehältnisse reaktiviert (Abb. I6) ${ }^{102}$ Die meisten dieser Wiederverwendungen können vor dem Hinter-

I02 Farioli Campanati ro89. 
grund eines neu aufkeimenden antiquarischen Interesses gesehen werden, eine Tendenz, die sich im I4. Jahrhundert noch verstärkte. In einer 1335 erstellten Liste von „Antiquitäten“, die der Trevisaner Notar und Kunstsammler Oliviero Forzetta in Venedig kaufen wollte, figurieren auch „quatuor pueri(s) de Ravenna lapidei(s), qui sunt taglati Ravenne in Sancto Vitale“, zu identifizieren mit zwei frühkaiserzeitlichen Eroten-Reliefs, auf denen die kleinen geflügelten Knaben mit den Insignien des Saturn spielend dargestellt sind. ${ }^{103}$ Die Reliefs befanden sich damals offenbar noch in Ravenna, waren aber schon für Venedig bestimmt, wohin sie auch verbracht wurden und wo sie verblieben, obwohl sich der Sammler aus Treviso sehr um sie bemühte; zunächst in die Außenwand eines Hauses in der Nähe des Markusplatzes eingemauert, wurden sie im späten I5. Jahrhundert, als dieses Haus abgerissen wurde, in die Kirche Santa Maria dei Miracoli überführt, von wo sie um I80o ins Museum transferiert wurden.

\section{Ausverkauf der Vergangenheit: Ravenna im 15. und 16. Jahrhundert}

Mit der Einverleibung Ravennas in venezianisches Herrschaftsgebiet im Jahre I44I erhielt der Zugriff Venedigs auf die ravennatischen Monumente eine neue Qualität. In den fast 70 Jahren venezianischer Herrschaft (I44I-I509) erfuhr Ravenna einen urbanistischen Modernisierungsschub, dem zahlreiche historische Bauten zum Opfer fielen. Für den Bau der Rocca Brancaleone 1457-I465 im Nordosten der Stadt musste beispielsweise die aus der Ostgotenzeit stammende Kirche S. Andrea dei Goti abgebrochen werden, deren Kapitelle ${ }_{4} 6_{3}$ im sog. Palazzo Veneziano an der Piazza del Popolo (Abb. I7) eine neue Heimat fanden. ${ }^{104}$

Venedig nutzte seine politische Überlegenheit aber auch dazu, wertvolle Baumaterialien aus Ravenna in die Lagunenstadt zu verschleppen. So wurde $1_{4} 65$ der komplette Säulensatz der Severuskirche in Classe, eines Baus aus der Zeit der Bischöfe Petrus III (569/70-578) und Johannes Romanus (578-595), ,05 nach Venedig verschifft, wobei von Sei ten der Serenissima die ravennatischen Klagen über diesen Verlust mit dem Argument abgewiegelt wurden, dass die kostbaren Werkstücke damit der eigensüchtigen Verkaufspraxis des Abtes von S. Apollinare in Classe entzogen und somit gleichsam "gerettet" seien. ${ }^{106}$

I03 Beschi I984-1985, 42f.; Favaretto 2002, 36. 68, Kat. I5f.; Beschi 2003. Weitere Fragmente desselben Monuments, verteilt über diverse oberitalienische Städte und außeritalienische Museen, sind zusammengestellt be Beschi $1984-1985$

O4 Ob auch die dort eingebauten Granitsäulen von dieser Kirche stammen, ist unklar; vgl. Giovannini/Rice 1985, I0I. I31, Anm. 69. Das übrige Baumaterial wurde hingegen im Fundament der Rocca verbaut; Fontana 1986, 296f. und Mascanzoni $1993,234 \mathrm{f}$

Io5 Kap. 93 und 98; Nauerth 1996,354 f. und $378 \mathrm{f}$.

Io6 Ricci 1909, I8-22; Ricci 1989, 537. 545f. S. Severo scheint 1465 so stark verfallen gewesen zu sein, dass die Kirche nicht mehr zu halten bzw, restaurierbar war, weshalb der Abbruch beschlossen wurde. Alles noch brauchGare Baumaterial sollte für einen Kirchenneubau, der neben der alten Kirche errichtet und ebenfalls dem hl. Se-
Abb. 17 | Ravenna, Palazzo Veneziano an der Piazza del Popolo: Arkatur mit Spoliensäulen und -kapitellen, die vermutlich von der um I 460 abgerissenen Kirche S. Andrea

dei Goti (493-526) stammen (Foto: C. Ja

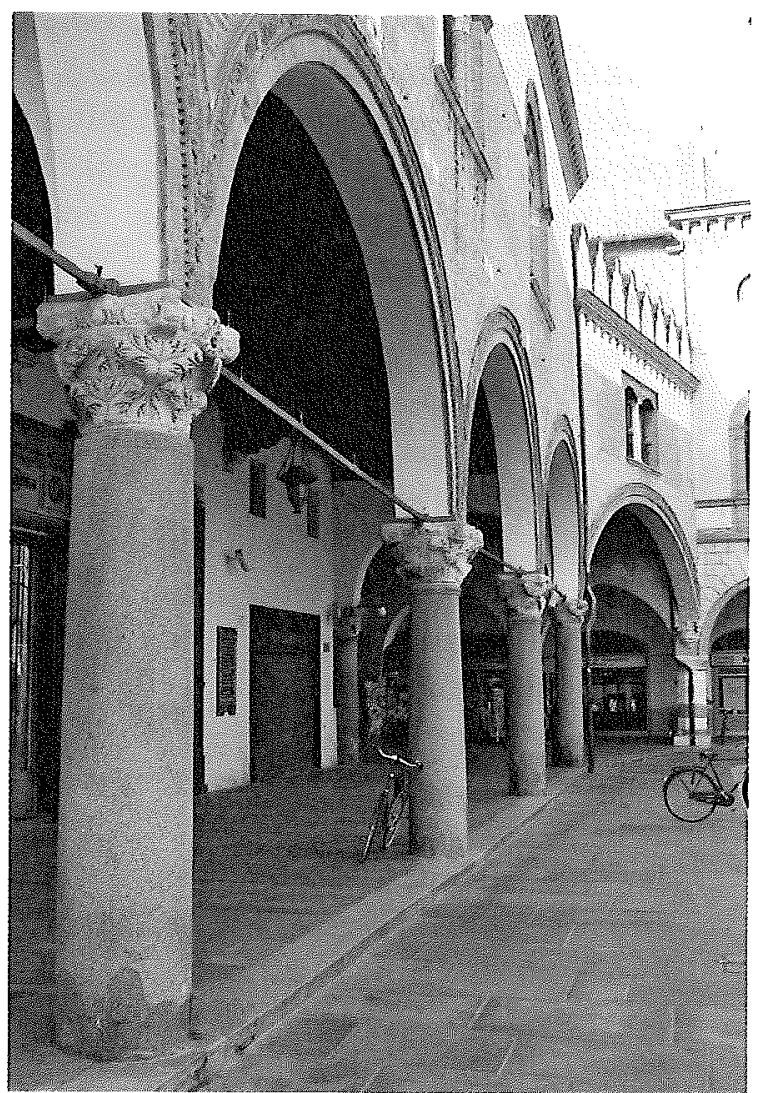

Kloster und Mönche von S. Apollinare in Classe - nota bene zum Großteil Venezianer spielten damals tatsächlich eine unrühmliche Rolle, was den Ausverkauf von Altertümern aus ihrem Besitz anbelangt; besonders einschneidend muss der kurz vor der Mitte des I5. Jahrhunderts erfolgte Verkauf von mehreren Wagenladungen Marmor aus der Classenser Apollinariskirche an Sigismondo Pandolfo Malatesta gewesen sein, die für die Erneuerung von S. Francesco in Rimini vorgesehen waren. ${ }^{\text {to7 }}$ Die Bereitwilligkeit des Klerus, die ererbten Wertgegenstände gegen Grundstücke und Immobilien zu veräußern, scheint in jenen Jahren so ausgeprägt gewesen zu sein, dass sich die venezianische Obrigkeit mehr-

verus geweiht sein sollte, wiederverwendet werden. Als sich aber der Neubau verzögerte, fanden einige Säulen den Weg nach Venedig, während andere offenbar schon am Hafen zum Versand bereit lagen. Die Oratorianer baten daraufhin den Dogen, dass sie das Material zurückbekämen; der Doge gab vor, dies zu unterstïtzen, und betonte dabei, dass er die Säulen nicht deshalb behändigt habe, um sie zu behalten, sondern um sie davor zu schützen, dass der Abt von S. Apollinare in Classe sie den Dominikanern von S. Giovanni e Paolo verkaufe (,nobis facta fuit instantia quod abbas Classis colonnas vendiderat, seu vendere volebat, fratribus SS. Ionanis et Pauli huius civitatis et lapides etiam erat venditurus"). Er versprach, sie zurückzuerstatten, doch zeigt der r648 schließlich realisierte Neubau von S. Severo, dass diese Rückerstattung nie erfolgte.

IO7 Ricci I909, I5-I7; Ricci 1989, 544-546; Mascanzoni 1993, 237. 
fach gemüßigt fühlte, dagegen einzuschreiten, so etwa anno 1474 im Falle des geplanten Verkaufs einer silbernen "Pala" durch den Ravennater Kathedralklerus, bei der es sich um nichts Geringeres gehandelt haben dürfte als um das Silberziborium, das Bischof Viktor um 540 an die Basilica Ursiana geschenkt hatte und das wenige Jahre später, im Sacco von 1512, von den Franzosen entführt und vermutlich eingeschmolzen wurde. ${ }^{\text {I08 }}$

In die Zeit, als Ravenna bereits wieder unter päpstlicher Herrschaft stand, fällt die bereits weiter oben erwähnte Spoliierung von S. Lorenzo im Jahre 1553. Dieser war eine längere Vorgeschichte vorausgegangen. Noch im späten 15. Jahrhundert war das außerhalb der Stadt liegende Kloster S. Maria in Porto Fuori aufgehoben und der Konvent in die Stadt hinein verlegt worden. Die Grundsteinlegung der neuen Konventsbauten erfolgte am 29. Juli I494, d.h. noch unter venezianischer Herrschaft, was sich auch darin zeigt, dass die im Kreuzgang verbauten Werkstiucke in Venedig fabriziert und in fertigem Zustand nach Ravenna exportiert wurden. ${ }^{109}$

Für die neue Klosterkirche, die erst danach entstand und - nicht zuletzt bedingt durch den Herrschaftswechsel - eine längere Planungs- und Bauzeit erlebte, wählte man hingegen einen anderen Weg. Hier sollten Spolien aus Ravenna zum Einsatz kommen, wofür die Regularkanoniker von S. Maria in Porto zunächst die Porta Aurea im Blick hatten. 1540 wurde der Prior von S. Maria in Porto beim Stadtrat von Ravenna vorstellig mit der Bitte, das römische Südtor, das damals weitgehend mit Erde und Buschwerk bedeckt war, auf eigene Kosten auszugraben, abzutragen und vor der neu zu errichtenden Klosterkirche S. Maria in Porto unter größter Sorgfalt im alten Zustand wieder aufzubauen. ${ }^{\text {IIO }}$ Nach einigen juristischen Quisquilien kam es in der Folge zwar zur Freilegung der Porta Aurea, nicht aber zu deren Ab- und Wiederaufbau im Dienste der neuen Klosterkirche; ob logistische Gründe dies verhinderten, ist den Quellen nicht zu entnehmen. Wir wissen nur, dass die Porta Aurea ein halbes Jahrhundert später, 1582 , auf Anweisung von Kardinal Guido Ferreri abgebrochen wurde, wobei ihr immerhin dadurch ein partielles Nachleben gesichert war, als ihre Reliefs in anderen Stadttoren Ravennas verbaut wurden und eines davon - die Porta Adriana - sogar das epitheton ornans „aurea“ übernahm. ${ }^{\text {III }}$

Die Regularkanoniker von S. Maria in Porto aber mussten sich für den Bau ihrer Klos terkirche nach einer anderen Baumaterialquelle umschauen. I553 erhielten sie schließlich die päpstliche Erlaubnis, die in Ruinen liegende Laurentiuskirche im alten Caesarea abzu-

I08 Ricci 1989, 548; Novara 1995b, 552. Zum "civorium de argento super altarium sanctae ecclesiae Ursianae" s. LPRav Kap. 66; Nauerth 1996, 292-295.

Io9 Fontana 1986, 300; vgl. Mattaliano I986, 357-359; Ricci 1989, 550; Mascanzoni 1993, 244.

IIO Kähler 1935, 173. Das entsprechende Dokument ist abgedruckt bei Ricci 1905, 32: „,... che con bona soddis factione et grande di questa Inclita et nobilissima patria e tutte sue spese con peritissimi et ingegniosissimi ma morarij et con ogni diligentissima diligentia et arte levarebbe dil detto luogo tutta l'antedetta porta dalli proprii fondamenti e le condurebbe su la Contrada di Piazza Maggiore, Et ivi nanti quel vacuo dove ha ad esser col tempo e in brevi edificata una magna chiesa, la farebbe nel proprio et medesmo modo et ordine che al presente se retrova. III Rubeus I590, 776; Fabri I678 (I966), 77f.; Kähler 1935, I72-I74; Ricci 1989, 553.

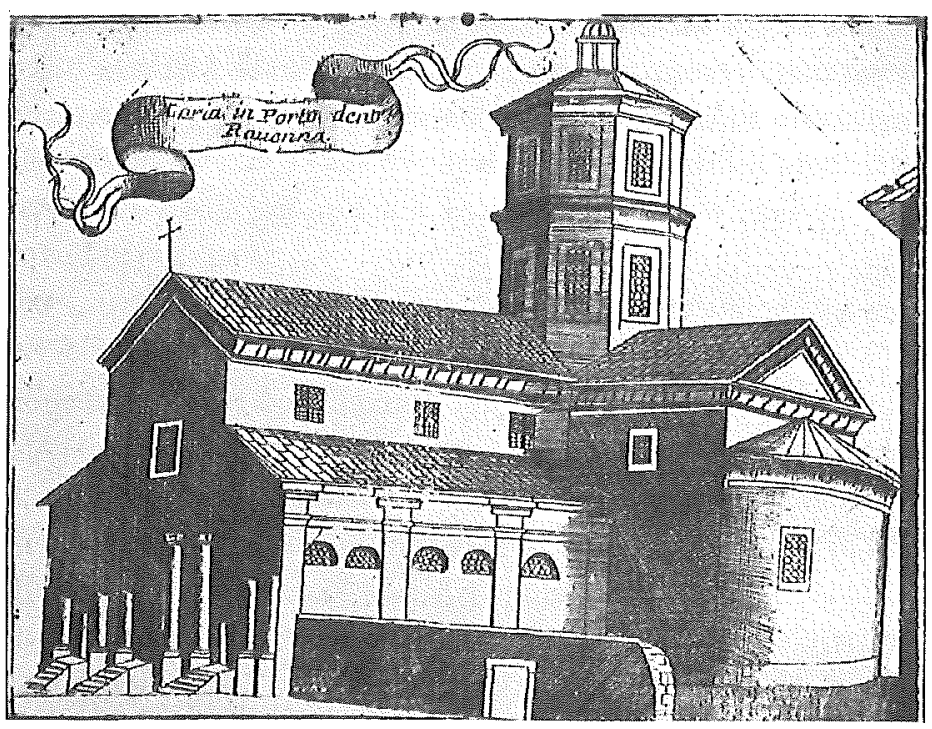

Abb. 18 | V. Coronelli, Stich von I698: Blick auf die Westfassade von S. Maria in Porto, mit Spoliensäulen, die auf ihren Versatz warten (aus: Mazzotti, Mario: Questioni portuensi. La facciata della basilica di S. Maria in Porto di Ravenna, in: Studi Romagnoli IV, I953, 250)

reißen und "lapides, cementa et ligna ac alia materia" wiederzuverwenden. ${ }^{\mathrm{II} 2}$ An Weihnachten 1554 war der Abbruch der obertägigen Baustrukturen von S. Lorenzo abgeschlossen, der Abbau der Fundamente erfolgte im darauffolgenden Jahr. ${ }^{\mathrm{II} 3}$

Dass von den Marmorsäulen, die das frühchristliche Gotteshaus in drei Schiffe geteilt hatten, sich nur einige versprengte Exemplare in der Klosterkirche von S. Maria in Porto finden, scheint mit dem Zugriff des damaligen Kardinallegaten für die Romagna, Girolamo Capodiferro, zusammenzuhängen, der die Säulen für Rom requiriert haben soll; die Quellenlage lässt jedoch keine Aussage darüber zu, ob der Spolientransport nach Rom tatsächlich zustande kam und wo die Säulen schließlich verbaut wurden. ${ }^{\mathrm{II}}$ Auf einem Stich von 1698, der S. Maria in Porto vor der Fertigstellung der Fassade zeigt (Abb. I8), sieht man neben zwei großen (Spolien-)Säulen fünf kleinere, die damals offen-

II2 Breve von Julius III. vom I6. Jan. I553, Archivio Storico Comunale die Ravenna, Pergamene, 335 rosso; Novara/Cicognani 1994, 225. Vgl. auch Rubeus I590, 6If.

II3 Novara/Cicognani 1994, $229 \mathrm{f}$.

II4 Der "Raub“ der Säulen von S. Lorenzo bzw. S. Maria in Porto durch Kardinal G. Capodiferro wird erstmals erwähnt von Fabri 1664, 228. Dass solche Antikentransporte auch scheitern konnten, zeigt der Fall der fünf Hermen aus dem 2. Jh., die sich heute im Museo Nazionale in Ravenna (Inv. Nrn. 345-349) befinden; sie wurden I936-I942 im Flussbett des Reno zwischen Casal Borsetti und Porto Corsini nördlich von Ravenna gefunden und scheinen Teil einer Schiffsladung gewesen zu sein, die $157 \mathrm{r}$ im Auftrag von Alfonso d'Este von Rom nach Ferrara gesandt worden und auf ihrem Weg mitsamt dem Transportschiff untergegangen war; vgl. Palma Venetucci I 64f., Anm. 16; Palma Venetucci 1992, 79f. Nr. 7 . 
bar für den Versatz bereit vor der Kirche standen; es liegt nahe, sie als Überreste aus der alten Laurentiuskirche anzusprechen, ebenso wie einige noch heute in S. Maria in Porto verbaute Werkstiucke aus kostbarem Steinmaterial, doch muss dies mangels Beweisen Hypothese bleiben. ${ }^{\text {II }}$

\section{Zusammenfassung}

Mit dem I6. Jahrhundert scheint die Fragmentierung der antiken und frühchristlichen Monumente ihren Höhepunkt erreicht zu haben; längst stand nicht mehr der Erhalt ganzer Ensembles im Mittelpunkt des Interesses, wie dies für die Frühzeit charakteristisch war, sondern das Einzelstück als Antiquität beziehungsweise Kuriosum. In derselben Zeit, wie in S. Vitale die frühkaiserlichen Erotenreliefs für ihre Kunstfertigkeit bewundert und angesichts ihrer stupenden Qualität sogar Praxiteles zugeschrieben wurden, scheute man nicht davor zurück, die Porta Aurea, die über I500 Jahre überdauert hatte, dem Erdboden gleichzumachen. An ihr interessierten die Reliefs, nicht das Monument als solches.

Ihren Höhepunkt hatte diese Tendenz im Dombau der r73oer Jahre, der die Werkstücke der frühchristlichen Vorgängerin in Form von deren in Scheiben gesägten Säulenschäften und Kapitellen in sich aufnahm, die im Bodenbelag der barocken Kirche ihre letzte Bestimmung fanden. Interessant ist die Beobachtung, dass die Säulen nicht lediglich als Materialspolien erachtet wurden, sondern insofern ein ästhetisches Eigenleben behielten, als die charakteristischen Plattenumrisse noch heute bestimmen lassen, ob die Platte aus einem Säulenschaft oder einem Kapitell geschnitten ist.

In den frühchristlichen Bauten Ravennas war dies völlig anders. Spolien wurden hier in der Regel ihres kostbaren Materials wegen verwendet, und alles scheint unternommen worden zu sein, um eine Einheitlichkeit der Bauglieder zu erzielen, auch wenn die Stückewie in S. Giovanni Evangelista - in Tat und Wahrheit heterogen waren. Spolien, die als solche erkannt wurden, scheinen sich auf den Palastbereich konzentriert zu haben, wo man vor allem an einer Kollektion von Buntmarmoren und Porphyr interessiert gewesen zu sein scheint, die am leichtesten in Rom zu haben waren. Gut möglich, dass bereits Theoderich durch seinen Spolienimport aus Rom für seinen ravennatischen Palast das alte caput mundi in Ravenna präsent machen wollte; Karl jedenfalls übertrug mit den Spolien aus Rom und Ravenna nach Aachen nicht nur tote Steine und Bronze, sondern auch ein Stück antiker beziehungsweise spätantiker Herrscherideologie.

Diese Erkenntnis ist keineswegs neu. Neu an der vorliegenden Studie ist ihr Längsschnittcharakter, der das (Selbst-)Recycling einer Stadt über mehrere Jahrhunderte thema-

II5 Novara/Cicognani 1994, 239-24I tisiert. II6 Recycling von Baumaterial war ein alltägliches Phänomen in der Vormoderne, doch lässt sich für Ravenna geradezu exemplarisch nachzeichnen, wie Phasen des Nehmens auf Phasen des Gebens folgten, vor allem aber auch, dass Recycling viele Gesichter haben konnte und selbst in ein und demselben Fall pragmatische Gründe neben ästhetischen und ideologischen den Ausschlag für die Wiederverwendung älterer Werkstücke gegeben haben kann.

\section{Bibliographie}

Alchermes 1994

Joseph Alchermes, „Spolia in Late Roman Cities of the Late Empire - Legislative Rationales and Architectural Reuse“, Dumbarton Oaks Papers 48, 165-178.

Ambrogi 1995

Annarena Ambrogi, Vasche di età romana in marmi bianchi e colorati, Rom.

Augenti 2005

Andrea Augenti, „Archeologia e topografia a Ravenna: il palazzo di Teoderico e la ,Moneta Aurea"', Archeologia Medievale 32, 7-33.

\section{Augenti 2008}

Andrea Augenti, „Le chiese e il contesto. Ravenna da città romana a capitale tardo antica“, in: Giuseppe Cuscito (Hg.), La cristianizzazione dell'Adriatico (Antichità Alto Adriatiche LXVI), Triest, 95-125.

Bauer 2009

Franz Alto Bauer, „Sagenhafte Herkunft. Spolien im Umkreis des byzantinischen Kaisers", in: Thomas G. Schattner/Fernando Valdés Fernández (Hgg.), Spolien im Umkreis der Macht. (Akten der Tagung in Toledo vom 2I. bis 22. Sept. 2006) Mainz, 59-80.

Bermond Montanari 1983

Giovanna Bermond Montanari, „La zona archeologica di Palazzolo", in: XXX Corso di Cultura sull'arte ravennate e bizantina (Seminario Giustinianeo, Ravenna 6-I4 marzo I983), Ravenna, $17-21$

Berti 1974

Fede Berti, Materiale dai vecchi scavi del palazzo di Teodorico, I, Le sculture“, Felix Ravenna CVII-CVIII, I5I-167.

\section{Berti 1975}

Fede Berti, „Materiale dai vecchi scavi del palazzo di Teodorico, II: Elementi di decorazione architettonica e frammenti diversi, Le sculture“, Felix Ravenna CIX-CX, 97-I27.

Ir6 Alchermes schlug vor, den negativ konnotierten Begriff der Spolie durch "recycling" zu ersetzen, da die Zeitgenossen durch die Wiederverwendung den Verfall aufhalten und dem Stadtbild seinen alten Glanz wiedergeben wollten; Alchermes 1994, I78. Esch 2005, 42 hingegen plädiert dafür, dort von Recycling statt von Wiederverwendung zu sprechen, wo das reine Material im Blick war und die Form des wiederverwendeten Stücks in Hinblick auf seine Neuverwendung verändert wurde. Vgl. zuletzt auch Verstegen (im Druck). 
Beschi $1984-1985$

Luigi Beschi, „I rilievi ravennati dei Troni“, Felix Ravenna CXXVII-CXXX, 37-80.

\section{Beschi 2003}

Luigi Beschi, „Quator pueri de Ravenna“, in: Mario Piana/Wolfgang Wolters (Hgg.), Santa Maria dei Miracoli a Venezia. La storia, la fabbrica, i restauri, Venedig, 203-209.

\section{Binding 2007}

Günther Binding, Antike Süulen als Spolien in früh-und hochmittelalterlichen Kirchen und Pfalzen - Materialspolie oder Bedeutunosträger? Sitzungsberichte der Wiss. Gesellschaft an der Johann Wolfgang Goethe-Univ. Frankfurt am Main, Bd. XLV, Nr. I, Wiesbaden.

Bosman 2004

Lex Bosman, The Power of Tradition. Spolia in the Architecture of St. Peter's in the Vatican, Hil versum.

\section{Bosman 2009}

Lex Bosman, „Spolien aus Roms Vergangenheit als Beitrag zu römischer oder romanischer Architektur", in: Leonhard Helten/Wolfgang Schenkluhn (Hgg.), Romanik in Europa. Kommunikation - Tradition - Rezeption, Leipzig, 37-51

\section{Bovini 1953}

Giuseppe Bovini: „Qualche appunto sull'antica cattedrale di Ravenna“, Felix Ravenna LXI, $59-84$.

\section{Brandenburg 1995}

Hugo Brandenburg, „Spolia ed elementi architettonici originali nella chiesa di S. Stefano Rotondo e nell'architettura tardo antica a Roma", in: XLI Corso di Cultura sull'Arte Ravennate e Bizantina (Seminario internaz. sul tema: „Ravenna, Costantinopoli, Vicino Oriente“, Ravenna 12-16 ott. 1994), Ravenna, 543-572.

\section{Brandenburg 1996}

Hugo Brandenburg: „Die Verwendung von Spolien und originalen Werkstücken in der spätantiken Architektur", in: Joachim Poeschke (Hg.), Antike Spolien in der Architektur des Mittelalters und der Renaissance, München, II-48.

\section{Brandenburg 2007/2008}

Hugo Brandenburg, „Magazinierte Baudekoration und ihre Verwendung in der spätantiken Architektur Roms des 4. und 5. Jahrhundert. Ein Beitrag zur Bewertung der Spolie", Boreas. Münstersche Beiträge zur Archäologie 30/31, I69-189.

\section{Brenk 1987}

Beat Brenk, „Spolia from Constantine to Charlemagne: Aesthetics versus Ideology", Dumbarton Oaks Papers 4I, 103-109.

\section{Capellini 1987}

Denis Capellini, „Considerazioni intorno al problema della cinta muraria di Ravenna tardoantica“, Felix Ravenna CXXXIII-CXXXIV, 8I-I20.

\section{Capellini 1993}

Denis Capellini, „Nuovi dati ed osservazioni sulla cinta muraria di Ravenna tardoantica“, Studi romagnoli 44, 3I-60.
Christie 1989

Neil Christie, "The City Walls of Ravenna: The Defence of a Capital, A.D. 402-750", in XXXVI Corso di cultura sull'arte ravennate e bizantina, Ravenna, Iз3-т 8 .

Christie/Gibson 1988

Neil Christie/Scheila Gibson, "The City Walls of Ravenna“, Papers of the British School at Rome 56, I56-197.

Coates-Stephens 2002

Robert Coates-Stephens, „Epigraphy as Spolia - the Reuse of Inscriptions", Papers of the British School at Rome $70,275-296$.

\section{Coates-Stephens 2003}

Robert Coates-Stephens, „Attitudes to Spolia in Some Late Antique Texts“, in: Luke Lavan/ William Bowden (Hgg.), Theory and Practice in Late Antique Archaeology, Leiden/Boston, $34 \mathrm{I}-358$.

Cortesi 1978

Giuseppe Cortesi, „La chiesa di Santa Croce di Ravenna alla luce degli ultimi scavi e ricerche“ in: XXV Corso di cultura sull'arte ravennate e bizantina, Ravenna, 47-76

\section{Crosara 1952}

Fulvio Crosara, „Federico II e Ravenna“, in: Atti di Studi Federiciani, Palermo, 255-28r.

\section{Deichmann 1969}

Friedrich Wilhelm, Deichmann, Ravenna. Geschichte und Monumente, Wiesbaden.

\section{Deichmann 1974}

Friedrich Wilhelm, Deichmann, Ravenna, Hauptstadt des spätantiken Abendlandes, Kommentar, . Teil, Wiesbaden.

\section{Deichmann 1975}

Friedrich Wilhelm, Deichmann, Die Spolien in der spätantiken Architektur (Sitzungsberichte der Bayerische Akad. der Wiss., Phil.-Hist. Klasse, Heft 6), München.

\section{Deichmann 1976}

Friedrich Wilhelm, Deichmann, Ravenna, Hauptstadt des spätantiken Abendlandes, Kommentar, 2. Teil, Wiesbaden.

\section{Deichmann 1989}

Friedrich Wilhelm, Deichman, Ravenna, Hauptstadt des spätantiken Abendlandes, Kommentar, 3. Teil, Wiesbaden.

\section{Deliyannis 20I0}

Deborah Mauskopf Deliyannis, Ravenna in Late Antiquity, New York.

\section{De Maria 2000}

Sandro De Maria, „Cultura figurativa: La decorazione architettonica“, in: Mirella Marini Calvani ( $\mathrm{Hg}$. Aemilia. La cultura romana in Emilia Romagna dal III secolo a. C. all'età costantiniana, Ausst.-Kat., Bologna/Venedig, 288-3r9. 


\section{Dinzelbacher 2010}

Briefe des Ostgotenkönigs Theoderich der Große und seiner Nachfolger. Aus den "Variae" des Cassiodor, eingeleitet, übersetzt und kommentiert von Peter Dinzelbacher, hg. von Ludwig Janus, Heidelberg.

\section{Dyggve 1956}

Ejnar Dyggve, „Basilica Herculis", in: Gertrude Gsodam (Hg.), Festschrift W. Sas-Zaloziecky zum 60. Geburtstag, Graz, 34-39.

\section{Elsner 2000}

Jas Elsner, From the Culture of Spolia to the Cult of Relics: The Arch of Constantine and the Genesis of Late Antique Forms“, Papers of the British School at Rome 68, 149-184

\section{Esch 1969}

Arnold Esch, „Spolien. Zur Wiederverwendung antiker Baustücke im mittelalterlichen Italien“, Archiv für Kunstgeschichte 5I, I-64.

Esch 2005

Arnold Esch, Wiederverwendung von Antike im Mittelalter, Berlin/New York.

\section{Fabri 1664}

Girolamo Fabri, Le sagre memorie de Ravenna antica, Venedig.

\section{Fabri 1678 (1966)}

Girolamo Fabri, Ravenna ricercata overo compendio istorico delle cose più notabili dell'antica città di Ravenna ora disoccupate, Bologna (Nachdruck Bologna I966).

\section{Fabricius Hansen 2003}

Maria Fabricius Hansen, The Eloquence of Appropriation. Prolegomena to an Understanding of Spolia, Rom.

\section{Fantuzzi 1803}

Marco Fantuzzi, Monumenti ravennati de' secoli di mezzo per la maggior parte inediti, $\mathrm{Bd}$. V, Venedig

\section{Farioli Campanati 1998}

Raffaella Farioli Campanati, „Note sui sarcofagi paleocristiani ravennati documentati a Ferrara nei reimpieghi dal XIII al XVII secolo", in: Studi in onore di G. Bovini, Bd. I, Ravenna, 245-256.

Fauvinet-Ranson 2006

Valérie Fauvinet-Ranson, Decor civitatis, decor Italiae. Monuments, travaux publics et spectacles au VIe siècle d'après les Variae de Cassiodore, Bari.

\section{Favaretto 2002}

Irene Favaretto, „Antikensammungen in Venedig: Ein historischer Streifzug vom I4. zum 19. Jahrhundert", in: Venezia! Kunst aus venezianischen Palästen. Sammlungsgeschichte Venedigs vom 13. bis 19. Jahrhundert, Ausst.-Kat., Bonn, 34-42.

\section{Fontana 1986}

Vincenzo Fontana, „De instauratione Urbis Ravennae. Architettura e urbanistica durante la dominazione veneziana“, in: Dante Bolognesi ( $\mathrm{Hg}$.$) , Ravenna in età veneziana, Ravenna,$ 295-304.
Forster 2009

Christian Forster, „Antike und byzantinische Kapitelle im ottonischen Magdeburg und ihre Herkunft“, in: Leonhard Helten/Wolfgang Schenkluhn (Hgg.), Romanik in Europa. Kommu nikation - Tradition - Rezeption, Leipzig.

\section{Gardini 2000}

Gabriele Gardini, „Le porte urbiche moderne“, in: Maurizio Mauro (Hg.), Mura, porte e torn di Ravenna, Ravenna, 210-263.

\section{Gelichi 2005}

Sauro Gelichi, „Le mura di Ravenna“, in: Ravenna da capitale imperiale a capitale esarcale. (Atti del XVII Congresso internazionale di studio sull'alto medioevo, Ravenna, 6.-I2. Juni 2004) Bd. II, Spoleto, $82 \mathrm{I}-840$.

\section{Giovannini/Ricci 1985}

Carla Giovannini/Giovanni Ricci, Ravenna (Le città nella storia d'Italia), Bari.

\section{Greenhalgh 2009}

Michael Greenhalgh, Marble Past, Monumental Present. Building with Antiquities in the Mediaeval Mediterranean, Leiden/Boston.

Hammer 2005

Carl I. Hammer, „Recycling Rome and Ravenna. Two Studies in Early-Medieval Reuse“, Saeculum 56, 295-325.

\section{Harper 1997}

ames G., Harper, „The Provisioning of Marble for the Sixth-Century Churches of Ravenna: A Reconstructive Analysis", in: Renate Colella et alii (Hgg.), Pratum Romanum. Richard Krautheimer zum 100. Geburtrstag, Wiesbaden, I3I-I48.

\section{Heidenreich/Johannes I97I}

Robert Heidenreich/ Heinz Johannes, Das Grabmal Theoderichs zu Ravenna, Wiesbaden.

\section{Jäggi 2010}

Carola Jäggi, „Edilizia religiosa a Ravenna, secoli V-VI", in: Sible de Blaauw, (Hg.), Storia dell'Architettura Italiana, Bd. ı: Da Costantino a Carlo Magno, Mailand, I46-189.

\section{ohnson 1988}

Mark J. Johnson, "Toward a History of Theoderic's Building Program", Dumbarton Oaks Papers 42, 73-96.

\section{Jurlaro 1986}

Rosario Jurlaro, Urbanistica nuova e recuperi dell'antico nelle Variae di Cassiodoro", in: Atti del VI Congresso nazionale di Archeologia Cristiana (Pesaro-Ancona I983). Bd. I, Florenz, I47-I5O.

\section{Kähler I935}

Heinz Kähler, Die Porta Aurea in Ravenna“, Mitteilungen des Deutschen Archäologischen Instituts, Römische Abteilung 50, 172-224. 
Kapitän I980

Gerhard Kapitän, „Elementi architettonici per una Basilica dal relitto navale del VI secolo di Marzamemi (Siracusa)", in: XXVII Corso di Cultura sull'Arte ravennate e bizantina, Ravenna, $7 \mathrm{I}-\mathrm{I} 36$.

\section{Kiilerich 2006}

Bente Kiilerich, „Antiquus et modernus. Spolia in Medieval Art - Western, Byzantine and Islamic", in: Quintavalle, Arturo ( $\mathrm{Hg}$ ), Medioevo: il tempo degli antichi. Atti del Convegno in. ternazionale di studi (Parma 24-28 settembre 2003), Milano, 135-I45.

\section{Kinney 1995}

Dale Kinney, "Rape or Restitution of the Past? Interpreting spolia“, in: Susan C. Scott (Hg.) The Art of Interpreting, University Park/PA 1995, 53-67.

\section{Lachenal 1995}

Dale de Lachenal: Spolia. Uso e reimpiego dell'antico dal III al XIV secolo, Mailand.

\section{La Rocca 1993}

Cristina La Rocca, „Una prudente maschera ,antiqua': la politica edilizia di Teodorico“, in Teoderico il Grande 2 i Goti d'Italia. (Atti del XIII Congr. internaz. di studi sull'Alto Medioevo, Mailand 2-6 novembre I992), Bd. II, Spoleto, 45I-5I5.

\section{Lippolis 2000}

Enzo Lippolis, „Cultura figurativa: La scultura ,colta' tra età repubblicana e dinastia antonina" in: Mirella Marini Calvani (Hg.), Aemilia. La cultura romana in Emilia Romagna dal III secolo a. C. all'età costantiniana, Ausst.-Kat. Bologna/Venedig 2000, 250-278.

\section{Liverani 2004}

Paolo Liverani, „Reimpiego senza ideologia. La lettura antica degli spolia dall'arco di Costantino all'età carolingia“, Mitteilungen des Deutschen Archäologischen Instituts, Römische Abteilung III, 383-434.

LP (Duchesne r886)

Le liber pontificalis. Texte, introduction et commentaire par L. Duchesne, Bd. I, Paris.

LPRav (Nauerth 1996)

Agnellus von Ravenna: Liber Pontificalis/Bischofsbuch, übersetzt und eingeleitet von Claudi Nauerth, Freiburg/Basel/Wien/Barcelona/Rom/New York.

\section{Manzelli 2000}

Valentina Manzelli, Ravenna (Atlante tematico di topografia antica, VIII suppl,; Città romane, 2), Rom.

\section{Mascanzoni 1993}

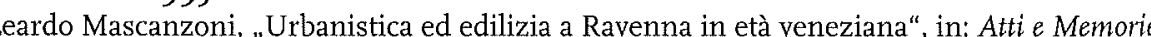
della Deputazione di Storia Patria per le provincie di Romagna n.s. XLIV, 225-252.

\section{Mattaliano 1986}

manuele Mattaliano, „La scultura a Ravenna nei luoghi e negli edifici pubblici fra Quattro e Cinquecento", in: Dante Bolognesi (Hg.), Ravenna in età veneziana, a cura di Dante Bolognes, Ravenna, 32I-366.
Mazzotti I95I

Mario Mazzotti, „La cripta della basilica Ursiana di Ravenna“, Felix Ravenna LV, 5-49.

Meckseper 200I

Cord Meckseper, „Magdeburg und die Antike. Zur Spolienverwendung im Magdeburger Dom", in: Matthias Puhle (Hg.), Otto der Große, Magdeburg und Europa, Ausst.-Kat. Magdeburg 200I, Bd. I: Essays, Mainz, 367-380

\section{Meier 2000}

Hans-Rudolf Meier, „Vom Siegeszeichen zum Lüftungsschacht. Spolien als Erinnerungsträger in der Architektur", in: Hans-Rudolf Meier/Marion Wohlleben (Hgg.), Bauten und Orte von Erinnerung. Die Erinnerungsdebatte und die Denkmalpflege, Zürich, 87-98.

\section{Meier 200I}

Hans-Rudolf Meier, „Der Begriff des Modernen und das Ende der Antike: Ein neuer Blick auf die materiellen Zeugen des Altertums“, in: Franz Alto Bauer/Norbert Zimmermann (Hgg.), Epochenwandel. Kunst und Kultur zwischen Antike und Mittelalter, Mainz, 67-74.

\section{Mirabella Roberti 1978}

Mario Mirabella Roberti, „Edilizia e architettura ambrosiana a Milano“, in: XXV Corso di Cultura sull'arte ravennate e bizantina, Ravenna, I9I-2IO.

\section{Monna/Pensabene/Sodini 198}

Dario Monna/Patrizio Pensabene/Jean Pierre Sodini, „L'identification des marbres: sa nécessité, ses méthodes, ses limites“, in: Patrizio Pensabene, (Hg.), Marmi antichi. Problemi d'impiego, di restauro e d'identificazione, (Seminario di archeologia e storia dell'arte greca e romana dell'Università die Roma „La Sapienza“, Studi miscellanei 26), Rom, I5-34.

\section{Müller 2009}

Rebecca Müller, „Antike im frühen Mittelalter. Erbe und Innovation“, in: Bruno Reudenbach (Hg.), Geschichte der bildenden Kunst in Deutschland, Bd. 1: Karolingische und ottonische Kunst, München/Berlin/London/New York, I9I-2I5.

\section{Novara 1995a}

Paola Novara, „Il pavimento medievale della cattedrale di Ravenna. Alcune note aggiuntive“, in: Irene Bragantini/Federico Guidobaldi (Hgg.), Atti del II Colloquio dell'Associazione Italiana per lo Studio e la Conservazione del Mosaico, (Roma 5-7 dic I994). Bordighera, $55 \mathrm{I}-560$.

\section{Novara 1995}

Paola Novara, „Edifici tardoantichi e medievali nelle descrizioni dei viaggiatori dei secoli XV-XVIII. Considerazioni minime intorno all'Appendice del Volume Storia di Ravenna, IV", Archeologia Medievale 22, 551-556.

\section{Novara 1997}

Paola Novara, La cattedrale di Ravenna. Storia e Archeologia, Ravenna.

\section{Novara $199^{8}$}

Paola Novara, "Capitelli antichi di Ravenna attraverso fonti iconografiche inedite", Ravenno. Studi e ricerche $\mathrm{V} / \mathrm{I}, \mathrm{I} 3-3 \mathrm{O}$ 
Novara 2008

Paola Novara, „Marmi dagli scavi di Santa Croce in Ravenna. Indagini sull'arredo architetto. nico e liturgico", Marmora 4, I07-I29.

\section{Novara/Cicognani 1994}

Paola Novara/Egle Cicognani, „L'atterramento di S. Lorenzo in Cesarea e la costruzione di S. Maria in Porto in Ravenna", Ravenna. Studi e ricerche I, 225-24I.

\section{Novara/Sarasini $200 \mathrm{I}$}

Paola Novara/Frederica Sarasini, Disiecta membra La scultura decorativa e i capitelli antichi di Ravenna", in: Maurizio Mauro (Hg.), Ravenna romana, Ravenna, 80-тo5.

Olivieri Farioli 1969

Rafaella Olivieri Farioli, La scultura archittetonica (= Corpus della scultura paleocristiana bizantina ed altomedioevale di Ravenna, Bd. III), Rom.

\section{Palma Venetucci 1992}

Beatrice Palma Venetucci (Hg.), Pirro Ligorio e le Erme tiburtine (Uomini illustrati dell'antichità I, I), Rom.

\section{Palma Venetucci $199^{8}$}

Beatrice Palma Venetucci (Hg.), Pirro Ligorio e le Erme tiburtine (Uomini illustrati dell'antichità I, I), Rom.

\section{Pensabene 1989}

Patrizio Pensabene Amministrazione dei marmi e sistema distributivo nel mondo romano", in: Gabriele Borghini (Hg.), Marmi antichi, Rom, 43-64.

Pugliese 2008

Raffaella Pugliese, „Il recupero del materiale nel medioevo. Dati dal cantiere di scavo dei SS. Quattro Coronati a Roma“, in: Jean-François Bernard/Philippe Bernardi/Daniella Esposito (Hgg.), Il reimpiego in architettura. Recupero, trasformazione, uso (Coll. de l'Ecole française de Rome 4I8), Rom, 329-336.

\section{Rebecchi 1974}

Fernando Rebecchi, „Immagini di equites romani su sarcofagi pagani di produzione ravennate“, Felix Ravenna CVII-CVIII, 4I-87.

Ricci 1905

Corrado Ricci, Raccolte artistiche di Ravenna, Bergamo.

\section{Ricci 1909}

Corrado Ricci, Marmi ravennati erratici. (Estratto da Ausonia. Rivista della società italiana di archeologia e storia dell'arte IV, fasc. II.).

Ricci I9I4

Corrado Ricci, „Il sepolcro di Galla Placidia in Ravenna“, Bollettino d'Arte, I-22.

\section{Ricci 1989}

Giavanni Ricci, „Ravenna spogliata fra tardo medioevo e prima età moderna“, Quaderni storici 7I, 537-56I.
Righini 199

Valeria Righini, „Materiali e tecniche da costruzione in età tardoantica e altomedievale“, in: Antonio Carile (Hg.), Storia di Ravenna II: Dall'età bizantina all'età ottoniana, parte 1: Territorio, economia e società, Venedig, 193-22.

\section{Romanelli 1996}

Rita Romanelli, „Reimpiego, tradizione e innovazione nell'architettura medievale di Ravenna", Arte Medievale, II ser., Anno X, No. I., 3I-45.

\section{Rosi I939}

Giorgio Rosi, „Ricerche intorno a Porta Aurea“, Felix Ravenna XLIV, fasc. I, 3I-43.

Rubeus $159^{\circ}$

Hieronymus Rubeus, Historiarum ravennatum libri decem, Venedig.

Saletti 1997

Cesare Saletti, Il Regisole di Pavia, Como.

\section{Story et alii 2005}

Joanna Story et alii, "Charlemagne's Black Marble: the Origin of the Epitaph of Pope Hadrian I", Papers of the British School at Rome 73, 157-I90.

\section{Thürlemann 1977}

Felix Thürlemann, „Die Bedeutung der Aachener Theoderich-Statue für Karl den Großen (80I) und Walahfrid Strabo (829). Materialien zu einer Semiotik visueller Objekte im frühen Mittelalter", Archiv für Kulturgeschichte 59, 25-66.

\section{Tigler 2006}

Guido Tigler, „I pilastri ,acritani'. Genesi dell'equivoco“, in: Giordana Trovabene (Hg.), Florilegium Artium. Scritti in memoria di Renato Polacco, Padua, 16I-172.

\section{Vernia 2009}

Barbara Vernia, Leggere i muri. Analisi degli edifici di culto nella Ravenna del V secolo d.C., Bologna.

\section{Verstegen (im Druck)}

Ute Verstegen, „Weihedenkmäler aus St. Gereon zu Köln - Spätantike Spoliennutzung als Ressourceneffizienz oder symbolischer Traditionsbruch?", in: Alfred Schäfer/Alexandra Busch (Hgg.), Römische Weihealtäre im Kontext.

\section{Verzone 1962}

Paolo Verzone, „La demolizione dei palazzi imperiali di Roma e di Ravenna nel quadro delle nuove forze politiche del sec. VIII", in: Festschrift Friedrich Gerke, Baden-Baden, 77-80.

\section{Ward-Perkins I95}

Bryan Ward-Perkins, „The Shrine of St. Peter and its Twelve Spiral Columns", Journal of Roman Studies 42, 21-33.

\section{Ward-Perkins 1984}

Bryan Ward-Perkins, From Classical Antiquity to the Middle Ages. Urban Public Building in Northern and Central Italy, AD 300-850, Oxford. 


\section{Ward-Perkins 1999}

Bryan Ward-Perkins, „Re-using the Architectural Legacy of the Past, entre idéologie et pragmatisme", in: Gian Pietro Brogiolo/Bryan Ward-Perkins (Hgg.), The Idea and the Ideal of the Town between Late Antiquity and the Early Middle Ages, Leiden, 225-244.

\section{Zanotto 2007}

Rita Zanotto, Vetusta servare. I reimpieghi di scultura architettonico-decorativa a Ravenna e nel ravennate tra tarda antichità e alto medioevo, Ravenna.

\section{Zanotto Galli 1995}

Rita Zanotto Galli, „Reimpieghi di scultura architettonica e rapporti con l'antico: il caso di Ravenna", in: XLII Corso di cultura sull'arte ravennate e bizantina (Seminario internazionale di studi sul tema: „Ricerche di Archeologia Cristiana e Bizantina“" In memoria del Prof. Giuseppe Bovini, Ravenna, I4-I9 maggio I995), Ravenna, 949-975.

\section{Zanotto Galli 2009}

Rita Zanotto Galli, „Committenza e reimpiego nell'architettura ravennate tra Tarda Antichità e Alto Medioevo", in: Farioli Campanati, Raffaella et alii (Hgg.), Ideologia e cultura artistica tra Adriatico e Mediterraneo orientale (IV-X secolo). Il ruolo dell'autorità ecclesiastica allo luce di nuovi scavi e ricerche, Atti del convegno internazionale (Bologna-Ravenna, 26-29 novembre 2007), Bologna 283-288.

\section{Zimmermann 1967}

Odo John Zimmermann, The Late Latin Vocabulary of the Variae of Cassiodorus. With Special Advertence to the Technical Terminology of Administration, Hildesheim.

\section{Radikale Rekontextualisierungen}

